University of Nebraska - Lincoln

DigitalCommons@University of Nebraska - Lincoln

2006

\title{
The GeoProfile Metadata, Exposure of Instruments, and Measurement Bias in Climatic Record Revisited
}

\author{
Rezaul Mahmood \\ University of Nebraska - Lincoln
}

Follow this and additional works at: https://digitalcommons.unl.edu/natrespapers

Part of the Natural Resources and Conservation Commons, Natural Resources Management and Policy Commons, and the Other Environmental Sciences Commons

Mahmood, Rezaul, "The GeoProfile Metadata, Exposure of Instruments, and Measurement Bias in Climatic Record Revisited" (2006). Papers in Natural Resources. 1273.

https://digitalcommons.unl.edu/natrespapers/1273

This Article is brought to you for free and open access by the Natural Resources, School of at DigitalCommons@University of Nebraska - Lincoln. It has been accepted for inclusion in Papers in Natural Resources by an authorized administrator of DigitalCommons@University of Nebraska - Lincoln. 


\title{
THE GEOPROFILE METADATA, EXPOSURE OF INSTRUMENTS, AND MEASUREMENT BIAS IN CLIMATIC RECORD REVISITED
}

\author{
REZAUL MAHMOOD,* STUART A. FOSTER and DAVID LOGAN \\ Department of Geography and Geology and Kentucky Climate Center, Western Kentucky University, Bowling Green, KY 42101, USA
}

Received 28 March 2005

Revised 10 November 2005

Accepted 12 November 2005

\begin{abstract}
Station metadata plays a critical role in the accurate assessment of climate data and eventually of climatic change, climate variability, and climate prediction. However, current procedures of metadata collection are insufficient for these purposes. This paper introduces the GeoProfile as a model for documenting and visualizing enhanced spatial metadata. In addition to traditional metadata archiving, GeoProfiles integrate meso-scale topography, slope, aspect, and land-use data from the vicinity of climate observing stations (http://kyclim.wku.edu/tmp/geoprofiles/geoprofiles_main.html). We describe how GeoProfiles are created using Geographical Information Systems (GIS) and demonstrate how they may be used to help identify measurement bias in climate observations due to undesired instrument exposures and the subsequent forcings of micro- and meso-environments. A study involving 12 COOP and US Historical Climate Network (USHCN) stations finds that undesirable instrument exposures associated with both anthropogenic and natural influences resulted in biased measurement of temperature. Differences in average monthly maximum and minimum temperatures between proximate stations are as large as 1.6 and $3.8^{\circ} \mathrm{C}$, respectively. In addition, it is found that the difference in average extreme monthly minimum temperatures can be as high as $3.6^{\circ} \mathrm{C}$ between nearby stations, largely owing to the differences in instrument exposures. Likewise, the difference in monthly extreme maximum temperatures between neighboring stations are as large as $2.4^{\circ} \mathrm{C}$. This investigation finds similar differences in the diurnal temperature range (DTR). GeoProfiles helped us to identify meso-scale forcing, e.g. instruments on a south-facing slope and topography, in addition to forcing of micro-scale setting. Copyright (C) 2006 Royal Meteorological Society.
\end{abstract}

KEY WORDS: GeoProfile; instrument exposure; measurement bias

\section{INTRODUCTION}

Quality of data plays a critical role in the accuracy of various climatic studies including climate variability, climate prediction, and climate change. The placement of instruments in poor localized exposures can yield data that are not representative of the environment being sampled, resulting in biased assessment of actual near-surface thermal conditions. Furthermore, the regional setting of a station may capture the forcing of predominant land use and land cover at meso- and regional scales. Adegoke et al. (2003), Mahmood and Hubbard $(2002,2003$, 2004) and Mahmood et al. (2002, 2004) demonstrated that land-use change could modify existing near-surface hydrologic and energy budget components and subsequently affect long-term thermal records. A series of studies by Balling (1988), Balling et al. (1998), Segal et al. (1989), Pielke (2002), Pielke et al. (2002a), Gallo et al. (1996, 1999), and Bonan (1999) show that land use affects the local thermal environment and subsequently the temperature records. In other words, it can be said that the exposure of instruments to local and regional land use influenced their observations.

We define poor instrument exposures as those in which site-related forcings that are not broadly representative of the surrounding region exert undue influence on the observations being collected. Forcings

\footnotetext{
* Correspondence to: Rezaul Mahmood, Department of Geography and Geology, Western Kentucky University, Bowling Green, Kentucky, KY 42101, USA; e-mail: rezaul.mahmood@wku.edu
} 
associated with the immediate site may derive from topographic slope and aspect, surface albedo, vegetation canopy, anthropogenic structures, and other features. On a larger scale, atmospheric forcings may be associated with topographic influences such as proximity to a body of water, location in a valley or on the windward or leeward slope of a mountain. Likewise, the anthropogenic impact of urbanization, even on a small scale, may influence observations. In cases where there is significant topographic, land-cover, or land-use variation, regional heterogeneity of the landscape may actually preclude the notion of a representative site.

To overcome these problems, the operational and scientific community has prescribed various guidelines for siting instruments and documenting the nature of their exposures. An example of siting guidelines is shown in conjunction with the new US Climate Reference Network (CRN) ( $c f$., Janis et al., 2004). In addition to fulfilling exposure requirements, it is necessary to keep detailed records of the surrounding physical setting, observation practices and their changes, data processing, and historical events. This information, known as metadata, not only helps in quality assurance of the data but also is essential for the accurate diagnosis and analysis of meteorological and climatological conditions. Historically, metadata have been recorded as hand written notes and, in some cases, in completed forms provided by the respective national meteorologi$\mathrm{cal} /$ climatological services. In the United States, the cooperative observation network (COOP) of the National Weather Service (NWS) is required to maintain metadata records in a form archived by the National Climatic Data Center (NCDC). Traditional elements of metadata include administrative information concerning the operation and maintenance of the station, documentation concerning the type of instrumentation in use at any given time, and changes in the location of a station. In addition, a simple sketch showing trees, buildings, and other relevant physical features that might have a bearing on the site may be included. Recently, more precise coordinates of latitude and longitude have been provided using global positioning system (GPS) receivers, and some of the cooperative observing sites are documented using photographs.

Selected COOP stations have been used to develop the US Historical Climate Network (USHCN) (Karl et al., 1990). These selections were completed after a screening process, established by the NCDC, which is supposed to 'ensure' homogeneity of the data and the station. The data from USHCN sites play a central role in the study of long-term climate variability and climate change. However, adequate metadata was not available in some screening processes, and the authors of this paper and others (cf., Davey and Pielke, 2005) have found that some of these USHCN stations have poor exposure and, thus, potentially provide us with biased temperature records.

The scientific community recognizes that the metadata base for climatological and meteorological data should be further expanded to aid the interpretation of climatic behavior (Aguilar et al., 2003). The Kentucky Climate Center's GeoProfile Initiative creates enhanced spatial metadata for COOP stations across the state. In this paper we will (i) document the development of station GeoProfiles using Geographical Information Systems (GIS) to integrate topographic and land-use information from the area surrounding an instrument site and (ii) report the descriptive analyses of potential impacts of instrument exposure on temperature records on the basis of information contained in a set of GeoProfiles.

We have investigated the mean maximum and minimum temperatures at monthly and annual timescales for selected locations. In addition, extreme monthly maximum and minimum temperatures and diurnal temperature range (DTR) were analyzed for the same sites. The length of the time series for this study is 1991 through 2000 and it is determined by the desire to have maximum homogeneity of the data and completeness of record for the selected sites. This investigation does not intend to show long-term trends or develop statistical hypothesis tests for station comparisons; however, it demonstrates bias in the data, identifies causes of the bias, and discusses how these biased data may provide inaccurate assessment of temperature variations. In our opinion, the results presented in this paper have significant implications relating to metadata and instrument exposure issues and consequently for climate variability and climate change studies.

Generally, near-surface temperature is a continuous field that does not change abruptly and shows only minor variations over short distances. Hence, it is expected that nearby stations (with moderate observation network density) should show consistently similar temperatures over time because they are supposed to be sampling essentially the same air mass and any impacts of land-atmosphere interactions should produce only minimal differences between the stations. However a deviation from this expectation may occur because of the exposure of instruments to undesired surfaces and structures and our inability to place them correctly as 
suggested in established guidelines. The analysis of temperature data from nearby stations, when supplemented with enhanced spatial metadata contained in GeoProfiles and other available 'traditional' metadata, can lead to an awareness and better understanding of the sources of bias that contaminate temperature records.

\section{BACKGROUND}

Explicit assessments and linking of the exposure of instruments to measurement bias are limited in the scientific peer-reviewed literature. Nearly all of the studies addressing this issue have been restricted to the urban heat island (UHI) effect and the resultant bias in the temperature records ( $c f$, Cayan and Douglas, 1984; Kukla et al., 1986; Epperson et al., 1995; Gallo et al., 1999). In addition, a number of studies assessed the time-of-observation bias (TOB) on temperature records ( $c f$, Schaal and Dale, 1977; Karl et al., 1986; Janis, 2002). Recently, several studies have estimated bias in measurements associated with the temperature recording instruments themselves (cf, Lin et al., 2001a, b, c; Hubbard and Lin, 2002; Hubbard et al., 2001). Another strand of study strives to identify and estimate the impacts of unknown sources of bias through the analysis of single or multiple station time series ( $c f$ Easterling and Peterson, 1995; Vincent, 1998; Allen and DeGaetano, 2000; Lund and Reeves, 2002). While these procedures may be effective, they highlight an inherent problem: the sources and effects of biases and heterogeneity must often be inferred because of limitations with historical metadata.

Note that undesired exposure is not limited to large urban areas, it may also occur in rural sites, predominantly agricultural locations, and in small urban areas. The present study, thus, focuses on these types of locations. Guidelines for siting meteorological stations have been developed in an effort to minimize the influence of site and locality biases. Exposures near natural or artificial obstructions are discouraged. While many COOP sites provide extended time series of temperature and precipitation observations that are highly valued for climate monitoring, a store of information suggests that the instrumentation is very often situated with suboptimal exposures.

It needs to be noted that in response to the concerns expressed in the literature (e.g. National Research Council, 1998) several steps have been undertaken to overcome some of the limitations. These include, among others, modernization of the COOP network (Horvitz and Leffler, 2002) and establishment of a new network known as the CRN (Janis et al., 2004). Both of these activities are currently underway. Up to this point in time, the metadata for the CRN sites do not call for the visualization and/or archiving of station exposures as presented here with the GeoProfile. However, it is indicative from the activities associated with the CRN and the various requirements for CRN station siting, station selection, and metadata archiving that the scientific and operational communities are aware of the limitations related to exposure and metadata and are willing to take necessary steps.

We suggest that GeoProfiles represent a step forward towards establishing a 'complete' station metadata containing information about its exposure and subsequent potential bias in measurements. It is expected that GeoProfiles, as illustrated here, would eventually be developed for all COOP, ASOS (Automated Surface Observing Network), CRN, mesonets and other similar climate and meteorological observing systems in the US and elsewhere in the world. Please note that the proposed COOP modernization activities will largely be involved in upgrading the instruments, achieving near-real-time internet-based data access, and increasing station density (Horvitz and Leffler, 2002). However, it is not clear how much of these efforts will involve the improvement of instrument exposure. Additionally, we will continue to use the data from these COOP stations in the near future for various basic scientific, applied, and operational research. Hence, an improvement in metadata archiving and availability for these COOP sites are essential for better interpretation of climatic data and accurate climatic analysis.

\section{EXPANDED METADATA: THE DEVELOPMENT OF GEOPROFILES}

Enhancements to existing metadata are essential if climatological networks are to produce high-quality data. It is not only crucial to document characteristics of the proximate landscapes that determine 
instrument exposures but also to do so in a way that those characteristics can be readily communicated to the users of climatological data. The Kentucky Climate Center has completed GeoProfiles for more than 20 COOP stations and plans to cover all of the more than 150 active stations in Kentucky (http://kyclim.wku.edu/tmp/geoprofiles/geoprofiles_main.html). Where possible, GeoProfiles will also be developed for stations that have closed down or moved out, but for which an extended period of record exists.

GeoProfiles synthesize available digital spatial data with data collected from site visits to climate stations. The Kentucky Office of Geographic Information (http://ogis.state.ky.us/) serves a wide variety of GIS databases, and two of these, digital elevation models (DEMs) and digital orthophotographs (DOQQs), are integrated into GeoProfiles. In addition, land-use data from the United States Geological Survey (USGS) and actual photographs taken on site are also included.

The DEMs are derived from USGS 7.5 min quadrangle map contour lines and have a horizontal resolution of $10 \mathrm{~m}$. (In contrast, many areas of the United States are still covered only by DEMs with a resolution of 30 meters.) While these DEMs provide substantially higher precision for representing topography of climate station sites, they also demand greater precision in locating climate stations. Coordinates from GPS, which are recorded to the nearest degree, minute, and second, provide locations only to within about $30 \mathrm{~m}$. DEMs are used in ESRI's ArcGIS and contribute to GeoProfiles in two respects. First, DEMs enable the construction of a three-dimensional visualization of topography for the area surrounding a station. Second, GIS functions can also be used to extract quantitative summary statistics concerning elevation, slope, and aspect that are characteristic of the station site and the surrounding concentric zones representing the immediate and extended vicinity. Currently, the Kentucky Climate Center is in the process of adding these quantitative summaries in the GeoProfile website. The present study also used these statistics to explain the findings. These summary statistics can then be compiled in a database for the purpose of comparing various stations.

DOQQs are aerial photographs that have been corrected to remove distortions introduced by the topography and camera angle. They are available through the USGS at a scale of $12000: 1$, and each image covers one quarter of an associated topographic quadrangle. DOQQs provide a visual representation of land use and land cover in the vicinity of the station. Though they represent a snapshot in time, DOQQs often provide evidence of recent land-use change. For example, DOQQs portraying station locations in urban cores, urban peripheries, or rural sites may imply quite different histories of anthropogenic impacts that could threaten the integrity of time series. The DOQQs available to be incorporated into GeoProfiles are mostly 5 to 10 years old, and site visits to stations often provide valuable information to supplement DEMs and DOQQs.

Site visits to climate stations provide a vital source of information. During the preparation of this manuscript, site visits were completed to 20 climate stations under the NWS cooperative observation network. Making site visits was time consuming and proved to be the primary limiting factor in developing GeoProfiles. The location of each station was recorded and then georeferenced using the appropriate DOQQ and DEM (Figure 1(a)-(e)). Where possible, and with permission from the observer, photographs were taken to provide further reference of the site. Subsequently, this information was stored and visualized as individual layers by using ESRI's ArcGIS software for GIS. Obviously, the above information is in addition to current metadata requirements. The information gained from site visits and sources such as the US Census can be used to construct a brief narrative that summarizes the locational setting of a station and documents the land-use- and land-cover changes at the site and in the locality of the station.

\section{METHODS}

To demonstrate potential impacts of the exposure of instruments with the aid of GeoProfiles, temperature data from 12 stations were selected (Figure 2) (Table I). An effort was made to select stations on the basis of completeness of record and homogeneity of data, though some of the stations were moved once during the period of investigation. Geographic proximity was the primary determinant used to group the stations into four sets, identified as Groups 1, 2, 3, and 4, with each group containing three stations. Neighboring stations were separated by an average of $34 \mathrm{~km}$. In each set, the stations showed minimum variation in latitude and elevation. Daily temperature records for the 10-year period from 1991 through 2000 were extracted from the 
(a)

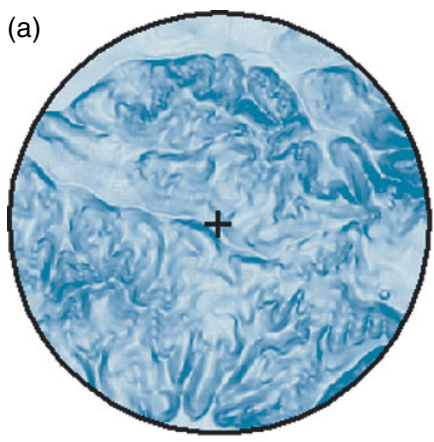

(b)

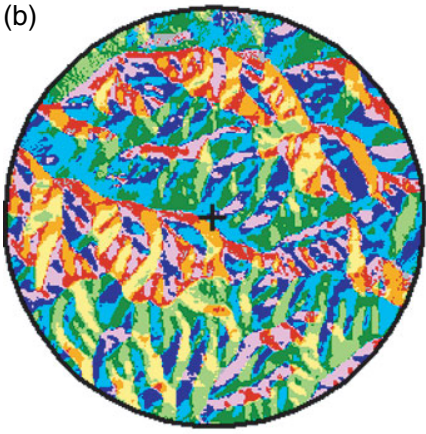

(c)

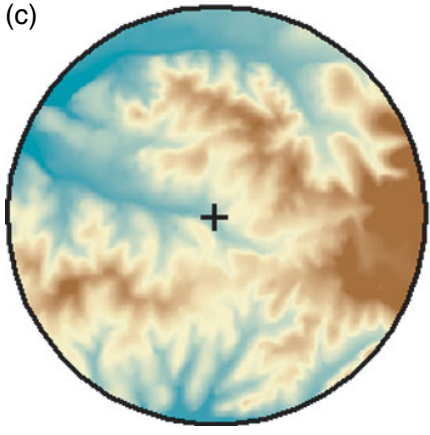

(d)
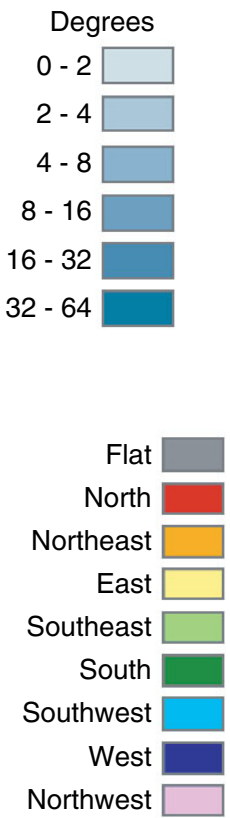

(e)

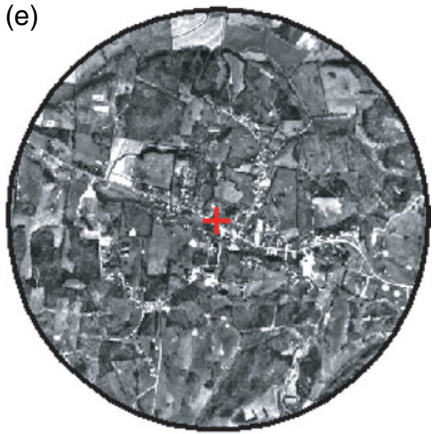

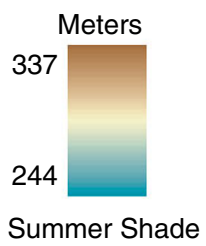

Figure 1. The GeoProfile of Summer Shade (SSH) station: (a) slope, (b) aspect, (c) elevation, (d) hill shade, and (e) land use. This figure is available in colour online at www.interscience.wiley.com/ijoc

'TD-3200 Summary of the Day data set' maintained by the NCDC. Among the chosen stations, the Glasgow (GLW) and Nolin River Lake (NRL) stations were moved in 1993, while the Mammoth Cave National Park (MCN) station was moved in 1999. Analyses involving these stations were based on truncated time series where appropriate.

Two sets of analyses were performed to assess seasonal temperature variations. Pairwise temperature comparisons were made for both daily maximum and daily minimum temperatures. No attempt was made to estimate values when daily observations were missing at either station. The mean temperature difference for each month of each year was then calculated for both maximum and the minimum temperatures, resulting in a total of up to 120 values for each. In the first set of analyses, averages were aggregated separately for each month to produce a 10 -year average of temperature differences for January, February, etc. The resulting means were then examined for seasonal patterns between paired stations. A second set of analyses was based on pairwise differences of the monthly extreme maximum and minimum temperatures for the paired stations. The first and last day of each month were deleted from the data set prior to searching for extreme temperatures. This eliminated time-of-observation effects, which could create an artificially large pairwise 


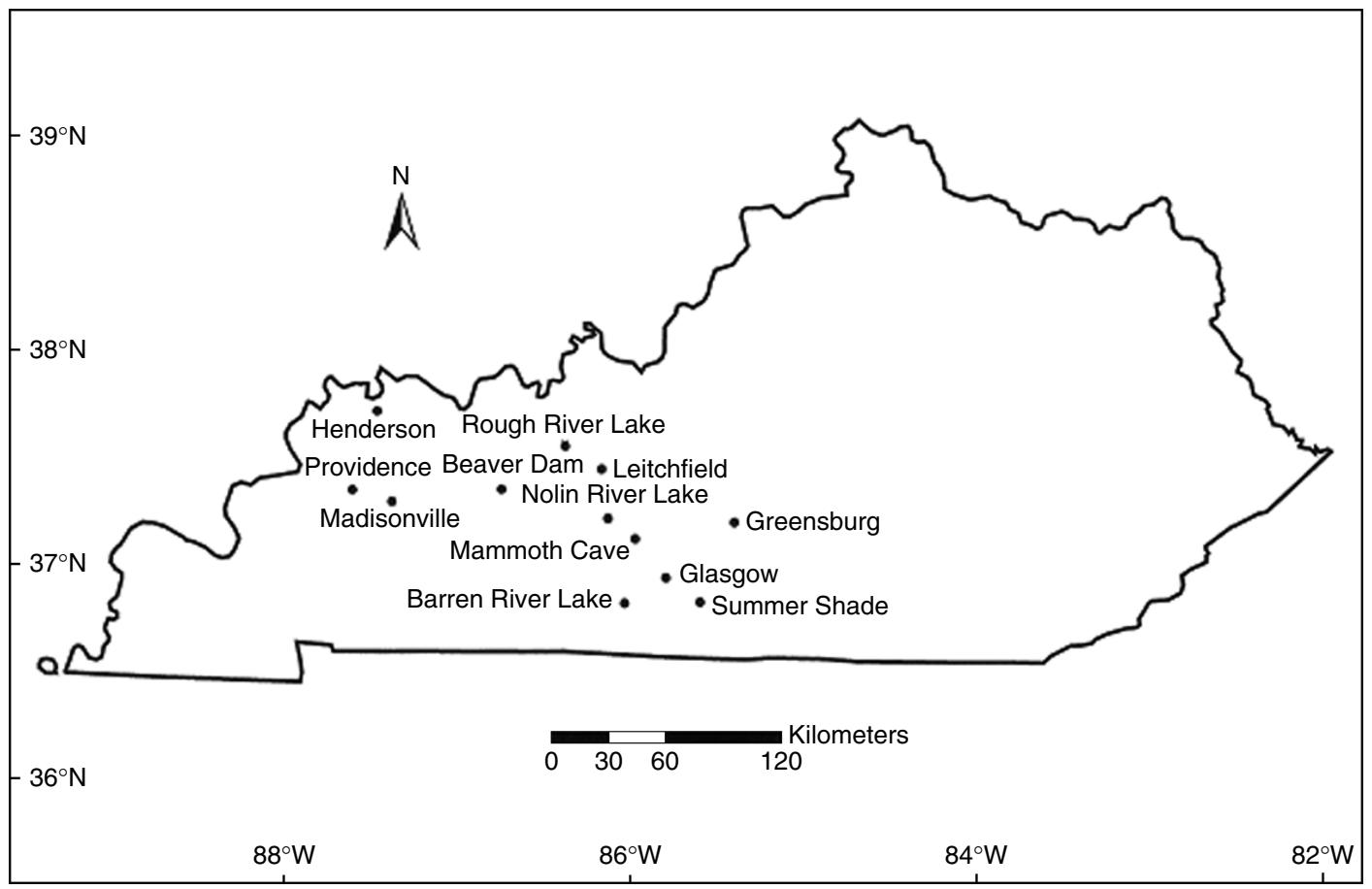

Figure 2. Location of meteorological stations used in this study

Table I. Location of COOP stations

\begin{tabular}{llll}
\hline Station and group & Latitude & Longitude & Elevation (meter) \\
\hline Group 1 & & & \\
Barren River Lake (BRL) & $36^{\circ} 54^{\prime}$ & $86^{\circ} 7^{\prime}$ & 189 \\
Glasgow (GLW) & $37^{\circ}$ & $85^{\circ} 54^{\prime}$ & 234.75 \\
Summer Shade (SSH) & $36^{\circ} 53^{\prime}$ & $85^{\circ} 42^{\prime}$ & 263.41 \\
Group 2 & & & \\
Nolin River Lake (NRL) & $37^{\circ} 17^{\prime}$ & $86^{\circ} 15^{\prime}$ & 207.31 \\
Mammoth Cave Park (MCN) & $37^{\circ} 11^{\prime}$ & $86^{\circ} 5^{\prime}$ & 240.85 \\
Greensburg (GRE) & $37^{\circ} 16^{\prime}$ & $85^{\circ} 30^{\prime}$ & 179.87 \\
Group 3 & $37^{\circ} 25^{\prime}$ & $86^{\circ} 53^{\prime}$ & 134.45 \\
Beaver Dam (BEA) & $37^{\circ} 31^{\prime}$ & $86^{\circ} 17^{\prime}$ & 189 \\
Leitchfield (LEI) & $37^{\circ} 37^{\prime}$ & $86^{\circ} 54^{\prime}$ & 170.73 \\
Rough River Lake (RRL) & $37^{\circ} 46^{\prime}$ & $87^{\circ} 38^{\prime}$ & 131.1 \\
Group 4 & $37^{\circ} 24^{\prime}$ & $87^{\circ} 46^{\prime}$ & 124.69 \\
Henderson (HEN) & $37^{\circ} 21^{\prime}$ & $87^{\circ} 31^{\prime}$ & 134.14 \\
Providence (PRO) & &
\end{tabular}

difference. Temperature differences were then averaged separately for each month of the year, resulting in 12 monthly averages, each based on a 10 -year record. This process was repeated for both the monthly maximum and minimum temperatures.

Another set of analyses was carried out to assess annual temperatures. Mean daily maximum and minimum temperatures were averaged to yield the corresponding annual averages for each year from 1991 through 2000. An additional data processing step was necessary because of the potential bias introduced when data 
for one or more months of a given year were missing. The magnitude of the bias would depend on the degree of seasonal variation in the temperature differences between paired sites. In response, each pairwise monthly temperature difference is taken as a deviation from the average pairwise temperature difference for that month on the basis of available data from the 10-year record. The annual pairwise temperature difference for a given year is then a sum of the monthly anomalies from the long-term average. As a result, the 10-year mean temperature difference between paired stations is removed from the data, but the variations in temperature differences can still be evaluated.

To further understand the impacts of exposure of instruments to surrounding micro- and meso-environment on temperature, quantitative estimates of the land use, slope, and aspect are completed using GeoProfiles. For this purpose, concentric (buffer) zones of 60,120,240,500, 1000, and $1500 \mathrm{~m}$ were created around each of the 12 stations and land-use, slope, and aspect classifications were completed. The actual area (in hectares) and the percentage of area covered by certain land use, slope, and aspect were also calculated for each of the concentric zones. This paper presents the calculated percentage of area covered by various land uses. These estimates have been used to explain various unusual variations of temperature among nearby sites. This study used the USGS classification scheme for land uses (http://landcover.usgs.gov/classes.asp). In this paper, micro-scale is defined as anything within $120 \mathrm{~m}$ of the station and meso-scale as anything outside $120 \mathrm{~m}$.

\section{EXPOSURE OF INSTRUMENTS AND ANALYSIS OF MONTHLY TEMPERATURE DATA}

Analyses presented in this section highlight seasonal effects evident in the mean maximum and minimum temperatures and in the mean monthly extreme maximum and minimum temperatures. In cases where a station was relocated, we use data only from the site that was active for the longer duration, between 1991 and 2000. The magnitude of seasonal variation in pairwise comparisons of neighboring stations provides an indication of the sensitivity of climatological data to station exposures. We refer to site and locality features documented in our GeoProfiles to offer physically plausible explanations of observed seasonal temperature patterns, though we cannot pretend to specify with certainty the nature of forcings at various scales that come to bear on a site.

\section{Group 1}

This group includes stations at Barren River Lake (BRL), GLW, and Summer Shade (SSH). As noted above, we expect that the additional metadata available through GeoProfiles would further explain the temperature differences among these locations, which are within a short distance. The BRL station is located near the BRL Dam on a small grassy site in immediate proximity to an asphalt parking lot. The site is not obstructed by vegetation. However, the instrument shelter is not built according to the NWS standards. Meanwhile, the SSH station (Figures $1(\mathrm{a})-(\mathrm{e}) ; 3$ ) is located on the lower portion of a SSW-facing slope in the backyard of a residence, with trees nearby. According to the GeoProfile, 63 and 50\% of the area within 60 and $120 \mathrm{~m}$ radius of the station, respectively, is developed, with a significant amount of vegetation and open spaces (Table II). The development includes residential units, and validates the on site-visit-based findings. However, the GeoProfile estimates that 75, 85, 93, and 97\% of the area within 240, 500, 1000, and $1500 \mathrm{~m}$ radius, respectively, of the SSH station is predominantly covered by vegetation (deciduous, evergreen, and mixed forests, grassy surfaces, and pastures) (Table II). The station at GLW (Figure 4(a)-(e)) is located in an older residential area, a few blocks from the central business district. The site is grassy with several small trees and shrubs. The GLW station was moved to its current location in late 1993, so the comparisons involving this site reflect only the period after 1993 . The GeoProfile suggests that $82,69,68,65,62$, and $52 \%$ of the area within $60,120,240,500,1000$, and $1500 \mathrm{~m}$ radius, respectively, of the GLW station is primarily under low- to medium intensity developments (Table III). The developments included both residential and other types of structures.

The analysis of data for Group 1 stations (Figure 5(a)-(c)) shows that the BRL site has higher average monthly maximum and minimum temperatures than the SSH site (Figure 5(b)) during the warm season, while 


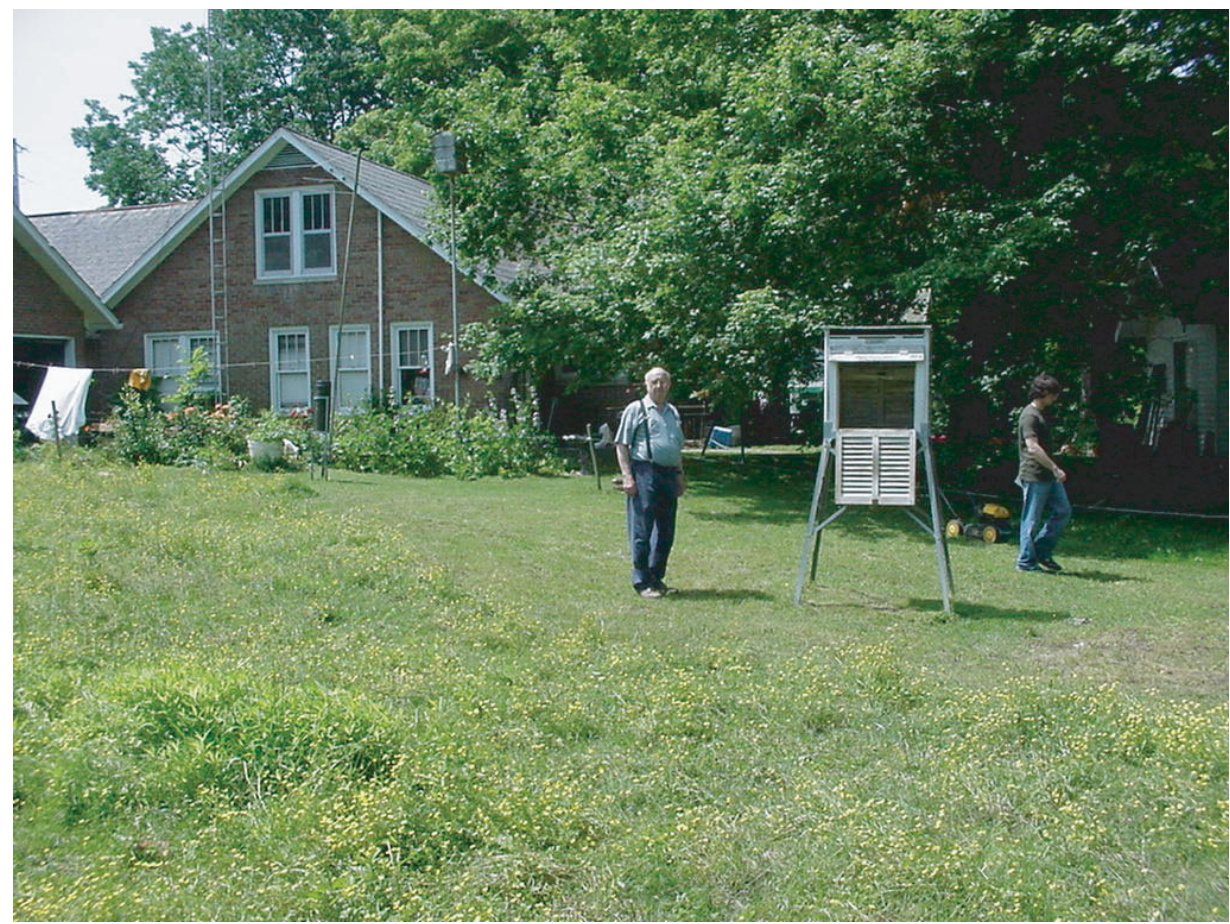

Figure 3. Exposure of temperature sensor at Summer Shade. This figure is available in colour online at www.interscience.wiley.com/ijoc

Table II. Land use (\%) within a predefined radius from the station at Summer Shade, KY

\begin{tabular}{lcccccc}
\hline Land use & $60 \mathrm{~m}(\%)$ & $120 \mathrm{~m}(\%)$ & $240 \mathrm{~m}(\%)$ & $500 \mathrm{~m}(\%)$ & $1000 \mathrm{~m}(\%)$ & $1500 \mathrm{~m}(\%)$ \\
\hline Open water & - & - & - & - & - & 0.01 \\
Developed, open space & 19.12 & 26.91 & 16.04 & 10.44 & 5.03 & 2.29 \\
Developed, low intensity & - & 0.37 & 1.20 & 1.12 & 0.28 & 0.12 \\
Developed, medium intensity & 43.38 & 22.26 & 8.46 & 3.58 & 1.28 & 0.61 \\
Developed, high intensity & - & - & - & - & - & - \\
Deciduous forest & 14.71 & 14.10 & 13.92 & 14.90 & 24.70 & 29.98 \\
Evergreen forest & - & 1.30 & 2.68 & 1.97 & 2.61 & 2.88 \\
Mixed forest & 11.76 & 19.29 & 19.09 & 18.83 & 15.80 & 14.89 \\
Planted/cultivated, pasture/hay & - & - & - & 13.93 & 32.86 & 36.61 \\
Planted/cultivated, row crops & - & 3.90 & 0.97 & 2.75 & 6.02 & 7.50 \\
Planted/cultivated, small grains & - & - & - & - & - & - \\
Recreational grasses, natural grasses & 11.03 & 11.87 & 37.63 & 32.47 & 11.42 & 5.10 \\
\hline
\end{tabular}

the temperature difference during the cool season is negligible. During warm season, the average monthly maximum and minimum temperatures of the BRL site can be higher by up to 1.6 and $1.2^{\circ} \mathrm{C}$, respectively. Also notable is the change of signs in the difference of average maximum and minimum temperature between the BRL and GLW (Figure 5(a)). The DTR at BRL is greater than at SSH and GLW during the warm (up to $0.6{ }^{\circ} \mathrm{C}$ ) and cool seasons (up to $0.4^{\circ} \mathrm{C}$ ) (Figure 5(a)-(c)). It is found that the DTR at GLW is larger than that at $\mathrm{SSH}$ during the warm season, while the opposite is true throughout much of the cool season (Figure 5(b) $-(\mathrm{c})$ ). Thus, we see a reversal of the magnitude of DTR with changes in the seasons.

Patterns in the seasonal variation of monthly extreme temperatures are also discernible. The monthly extreme maximum temperatures are consistently warmer at BRL compared to GLW and SSH, and consistently higher 

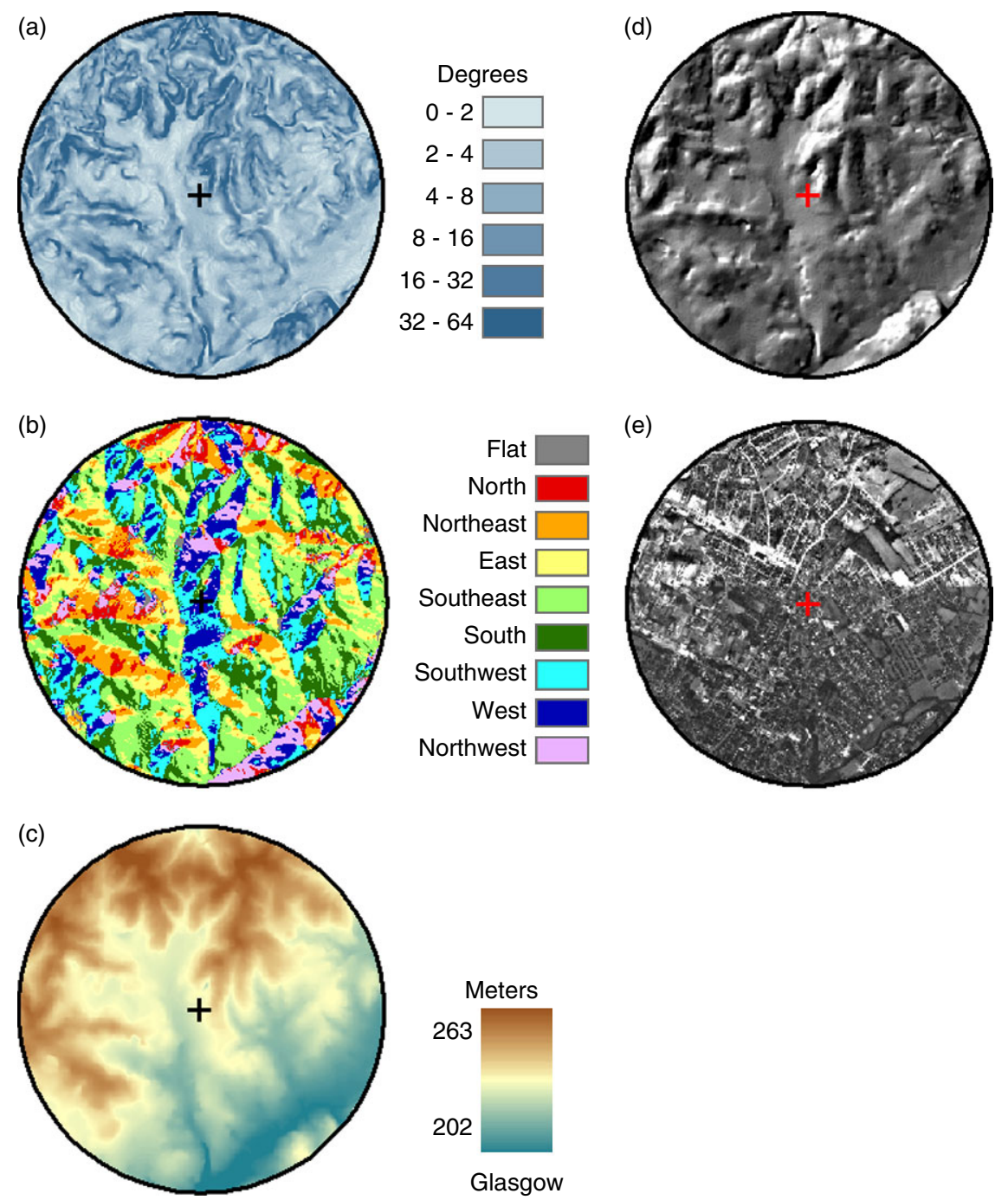

Figure 4. (a-e) Same as in Figure 1, except for Glasgow. This figure is available in colour online at www.interscience.wiley.com/ijoc

at GLW compared to SSH (Figure 6(a)-(c)). At BRL, compared to GLW and SSH, it is higher by up to 1.2 and $2.3^{\circ} \mathrm{C}$, respectively. Compared to GLW, the monthly extreme minimum temperatures are also higher by up to $1.7^{\circ} \mathrm{C}$ at BRL during most of the year except for the winter months (Figure 6(a)). Moreover, it is higher at BRL (up to $2.6^{\circ} \mathrm{C}$ ) and GLW (up to $3.2^{\circ} \mathrm{C}$ ) compared to SSH for all months of the year (Figure 6(b) $-(\mathrm{c})$ ). The most complex pattern is evident when comparing GLW and SSH. While GLW produces higher extreme temperatures, the largest difference in the extreme maximum temperature occurs during the warm season, while the greatest difference in the extreme minimum $\left(3.2^{\circ} \mathrm{C}\right)$ is evident during the cool season (Figure $6(\mathrm{c})$ )).

The GeoProfile for BRL suggests that the instrument is located on a nearly flat surface with the lake in fairly close proximity. We suggest that the warm season higher monthly maximum temperature at BRL compared to SSH is primarily forced by the asphalt pavement. It is also shown above that the area between 120 and $1500 \mathrm{~m}$ radius of the SSH is predominantly covered by vegetation (Table II), which provides cooling effect. There is no clear evidence of a lake breeze in the warm BRL temperature records; otherwise the station would have had moderate temperatures compared to SSH. During the cool season, the SWW aspect (82\% area within $60 \mathrm{~m}$ radius of the station; Table IV) helps SSH (Figure 1(a)-(e)) to attain temperatures comparable to asphalt surfaces. It is also found that $62,47,35,32$, and $33 \%$ of the land within $120,240,500,1000$, and 
Table III. Land use (\%) within a predefined radius from the station at Glasgow, KY

\begin{tabular}{lcccccc}
\hline Land use & $60 \mathrm{~m}(\%)$ & $120 \mathrm{~m}(\%)$ & $240 \mathrm{~m}(\%)$ & $500 \mathrm{~m}(\%)$ & $1000 \mathrm{~m}(\%)$ & $1500 \mathrm{~m}(\%)$ \\
\hline Open water & - & - & - & - & 0.06 & 0.09 \\
Developed, open space & 72.73 & 61.22 & 47.26 & 46.04 & 38.42 & 31.21 \\
Developed, low intensity & 9.09 & 6.12 & 15.92 & 16.19 & 14.73 & 11.75 \\
Developed, medium intensity & - & 2.04 & 4.48 & 2.99 & 9.03 & 9.26 \\
Developed, high intensity & - & - & - & - & - & - \\
Deciduous forest & - & 4.08 & 8.96 & 13.78 & 14.38 & 13.82 \\
Evergreen forest & - & - & - & 0.80 & 0.26 & 0.62 \\
Mixed forest & 18.18 & 12.24 & 8.96 & 9.30 & 8.57 & 8.97 \\
Planted/cultivated, pasture/hay & - & - & - & - & 1.26 & 5.77 \\
Planted/cultivated, row crops & - & - & - & - & 2.21 & 3.41 \\
Planted/cultivated, small grains & - & - & - & - & - & - \\
Recreational grasses, natural grasses & - & 14.29 & 14.43 & 10.91 & 11.09 & 15.09 \\
\hline
\end{tabular}

$1500 \mathrm{~m}$ radius, respectively, have a predominantly SSW aspect (Table IV). We speculate that the draining of cooler air in the evenings during the cool season reduces the minimum temperatures at SSH, which is similar to the radiative cooling of the asphalt-covered surface in the vicinity of BRL station. Switching of signs (from positive to negative and vice-versa) of the differences in the average maximum and minimum temperatures and reversal of the magnitude in DTR between BRL and GLW are related to the nonlinear forcing of the surrounding settings around instruments in cool and warm seasons. Moreover, reversal of the magnitude in DTR between BRL and SSH can also be associated with the same cause. Hence, exposure of instruments to the surrounding micro- and meso-scale anthropogenic and natural settings (which are not conforming to the established guidelines) results in biased records between two nearby locations. The GeoProfile, which captures various parameters of local topography, provides quantitative estimates, and identifies anthropogenic modifications (for example, land use), has been particularly helpful in providing a more complete explanation of these temperature differences between SSH and BRL stations. Traditional site description and photographs could only partly explain these disagreements between two fairly nearby locations.

The forcing of surrounding elements and exposure is more prominent in extreme monthly maximum and minimum temperatures. The BRL and GLW stations systematically reported higher extreme monthly maximum and minimum temperatures compared to SSH. Exposure of BRL to the nearby asphalt surface and the surrounding urban location at GLW forced (Table III) a higher extreme temperature at these stations compared to SSH. The extreme maximum temperatures are always higher at BRL compared to GLW. However, the extreme minimum temperatures are lower in BRL during cool months while it is higher during warm months. During warm months, the forcing of asphalt is greater compared to the UHI effect in GLW. As a result, the extreme minimum temperatures are higher at BRL. On the other hand, during cool months, the forcing of $\mathrm{UHI}$ is greater than that of asphalt alone in BRL and thus resulted in higher extreme minimum temperatures. The GeoProfiles for these locations, again, were particularly helpful in capturing a complete picture of the surrounding micro- and meso-scale setting and explaining the findings.

\section{Group 2}

This group consists of stations at Greensburg (GRE), MCN, and NRL. The MCN station is located in a meadow within an otherwise forested area. Physiographically, the site is a plateau and without significant relief in the immediate area. However, the location of MCN is significantly higher in elevation than the Green River, which runs through the park. The NRL station is situated on a SW-facing slope near the top of a hill. A spillway is cut through the hill adjacent to the station resulting in a steep slope that drops approximately 75 feet to the spillway. The site is close to an asphalt parking lot and other paved surfaces. The GRE station is located near the central business district of this small town with a population of nearly 2400 (Figures 7 
(a) Monthly Mean Temperature
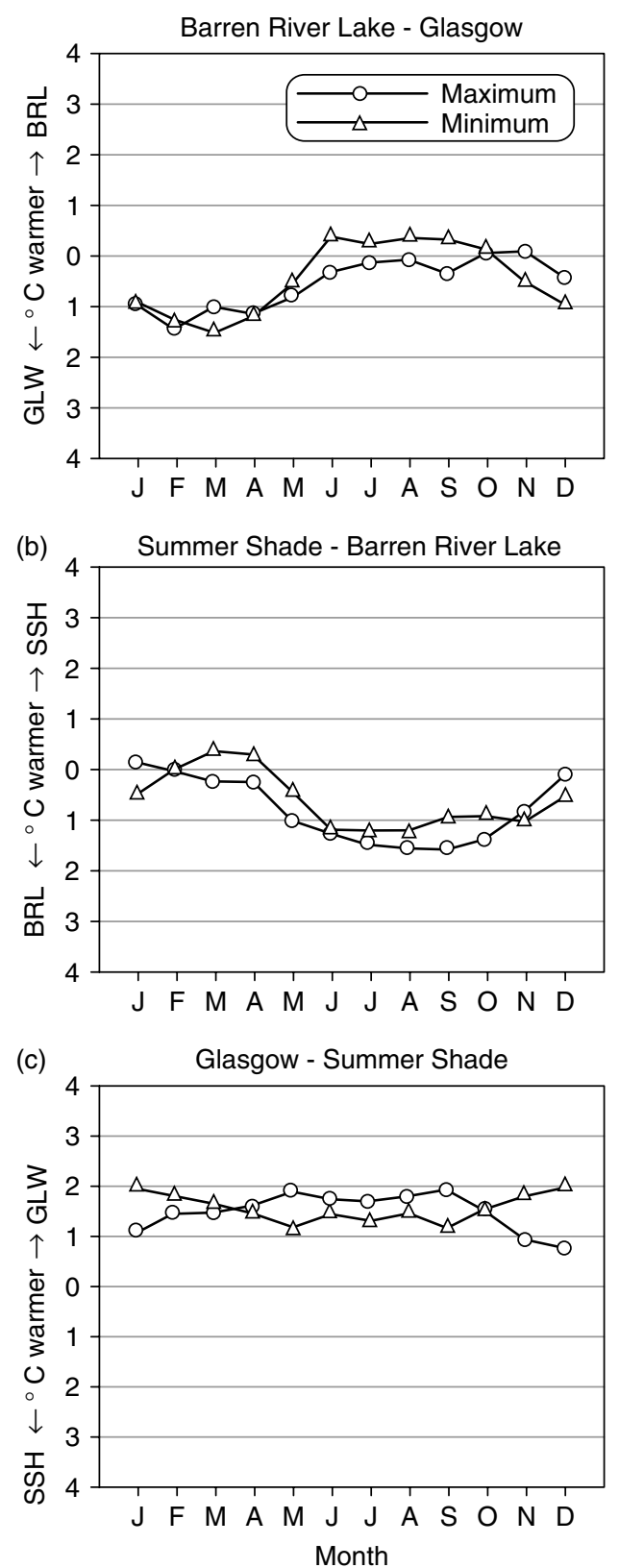

Figure 5. Pairwise mean maximum and minimum temperature difference between: (a) Barren River Lake and Glasgow, (b) Summer Shade and Barren River Lake, and (c) Glasgow and Summer Shade

and 8). The temperature sensor is located on the upper portion of an ESE-facing slope over a small grassy area in front of a building, and is surrounded by asphalt, concrete, and brick and block buildings.

The analysis of data shows that the average monthly minimum temperatures are significantly warmer, up to $1{ }^{\circ} \mathrm{C}$, at MCN than nearby NRL for six months in a year (Figure 9(a)). The NRL station appears to be more sensitive to seasonal variations, as the average monthly maximum temperatures become higher, up to $1.5^{\circ} \mathrm{C}$, at NRL during the warm season. The average monthly maximum and minimum temperatures follow 
(a) Monthly Extreme Temperature

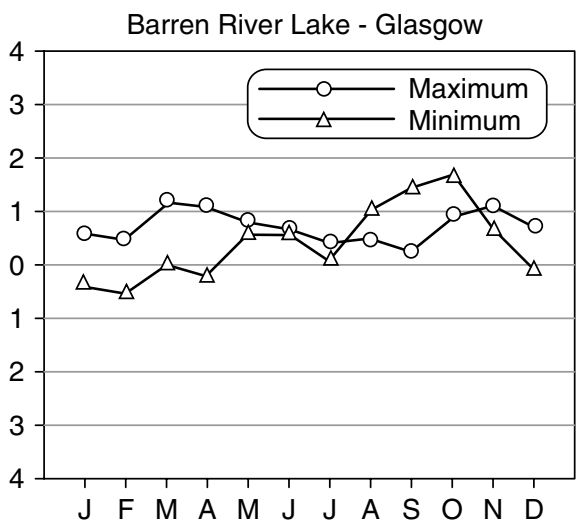

(b) Summer Shade - Barren River Lake

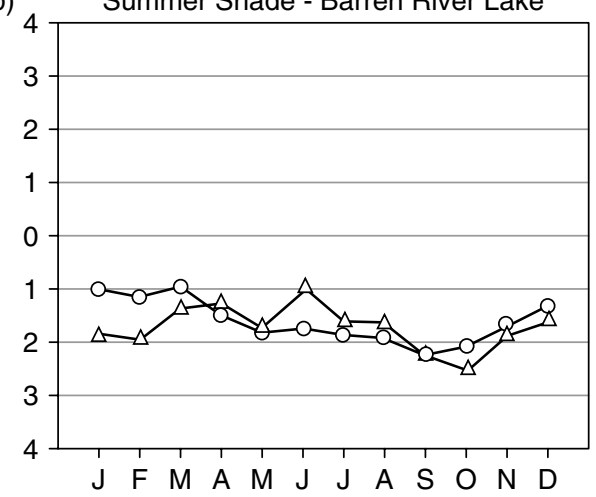

(c)

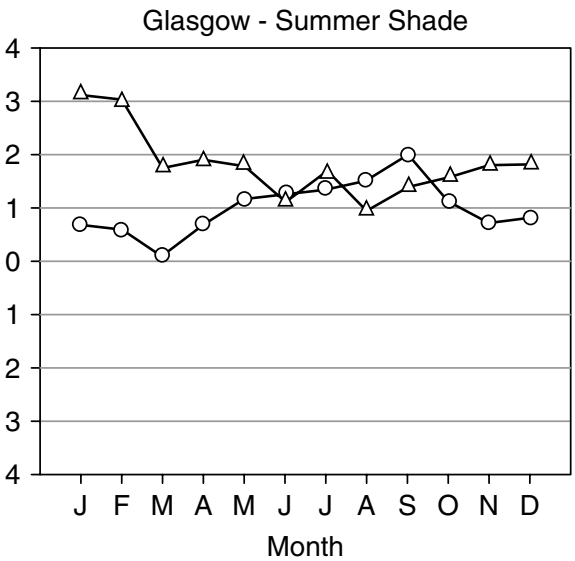

Figure 6. Pairwise mean extreme maximum and minimum temperature difference between: (a) Barren River Lake and Glasgow, (b) Summer Shade and Barren River Lake, and (c) Glasgow and Summer Shade

a similar pattern of seasonal variations at MCN and GRE (Figure 9(b)). However, it appears that GRE is more sensitive to increased day length in late spring and early summer. The DTR at MCN is up to $1{ }^{\circ} \mathrm{C}$ higher than that at GRE during the first half of a year (Figure 9(a)-(b)). This situation reverses during the final quarter of a year for these two stations (Figure 9(a)-(b)). However, the difference of DTR between these two stations is not as great during cool months. Furthermore, the DTR at NRL remains lower compared to MCN for all months of a year, except during June through September. The difference increases up to 
Table IV. Aspect (\%) within a predefined radius from the station at Summer Shade, KY

\begin{tabular}{lcccccc}
\hline Aspect & $60 \mathrm{~m}(\%)$ & $120 \mathrm{~m}(\%)$ & $240 \mathrm{~m}(\%)$ & $500 \mathrm{~m}(\%)$ & $1000 \mathrm{~m}(\%)$ & $1500 \mathrm{~m}(\%)$ \\
\hline Flat & 0.74 & 0.19 & 0.74 & 1.64 & 1.20 & 1.66 \\
North & 1.47 & 3.90 & 7.81 & 9.63 & 10.78 & 9.65 \\
Northeast & - & 16.14 & 10.59 & 9.24 & 8.81 & 8.67 \\
East & - & - & 2.40 & 4.45 & 8.54 & 8.37 \\
Southeast & - & - & 5.55 & 8.92 & 10.37 & 10.91 \\
South & 4.41 & 8.35 & 18.40 & 18.95 & 15.94 & 15.36 \\
Southwest & 41.18 & 45.08 & 33.33 & 19.52 & 16.08 & 16.77 \\
West & 41.18 & 17.07 & 13.27 & 15.19 & 15.64 & 16.04 \\
Northwest & 11.03 & 9.28 & 7.91 & 12.45 & 12.63 & 12.57 \\
\hline
\end{tabular}
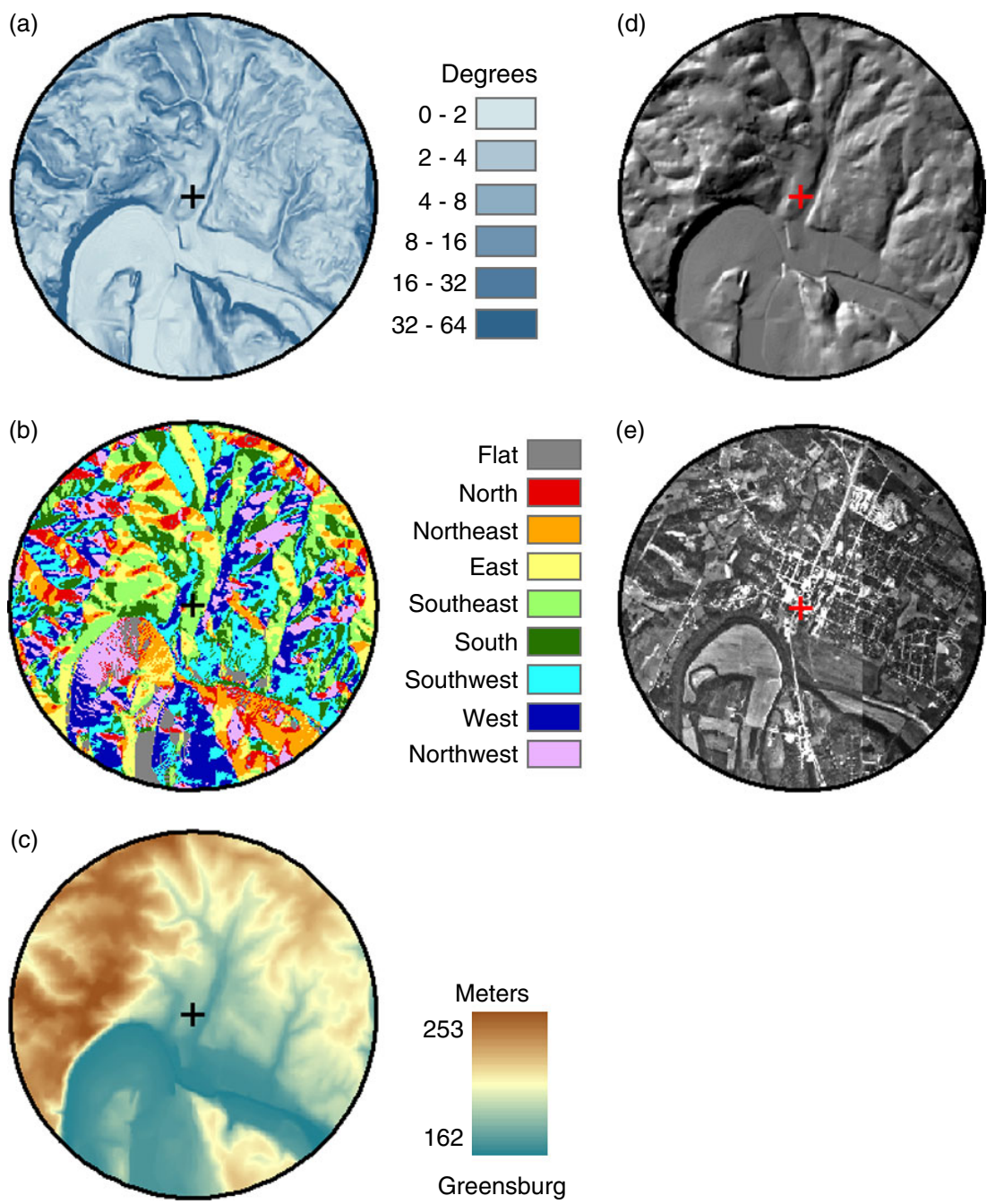

Figure 7. (a-e) Same as Figure 1, except for Greensburg. This figure is available in colour online at www.interscience.wiley.com/ijoc

$1.5^{\circ} \mathrm{C}$ during warm months. The comparison of DTR between GRE and NRL shows that it is higher at NRL throughout the year (Figure 9(c)). The difference reaches up to $2.0^{\circ} \mathrm{C}$ during warm months. The average 


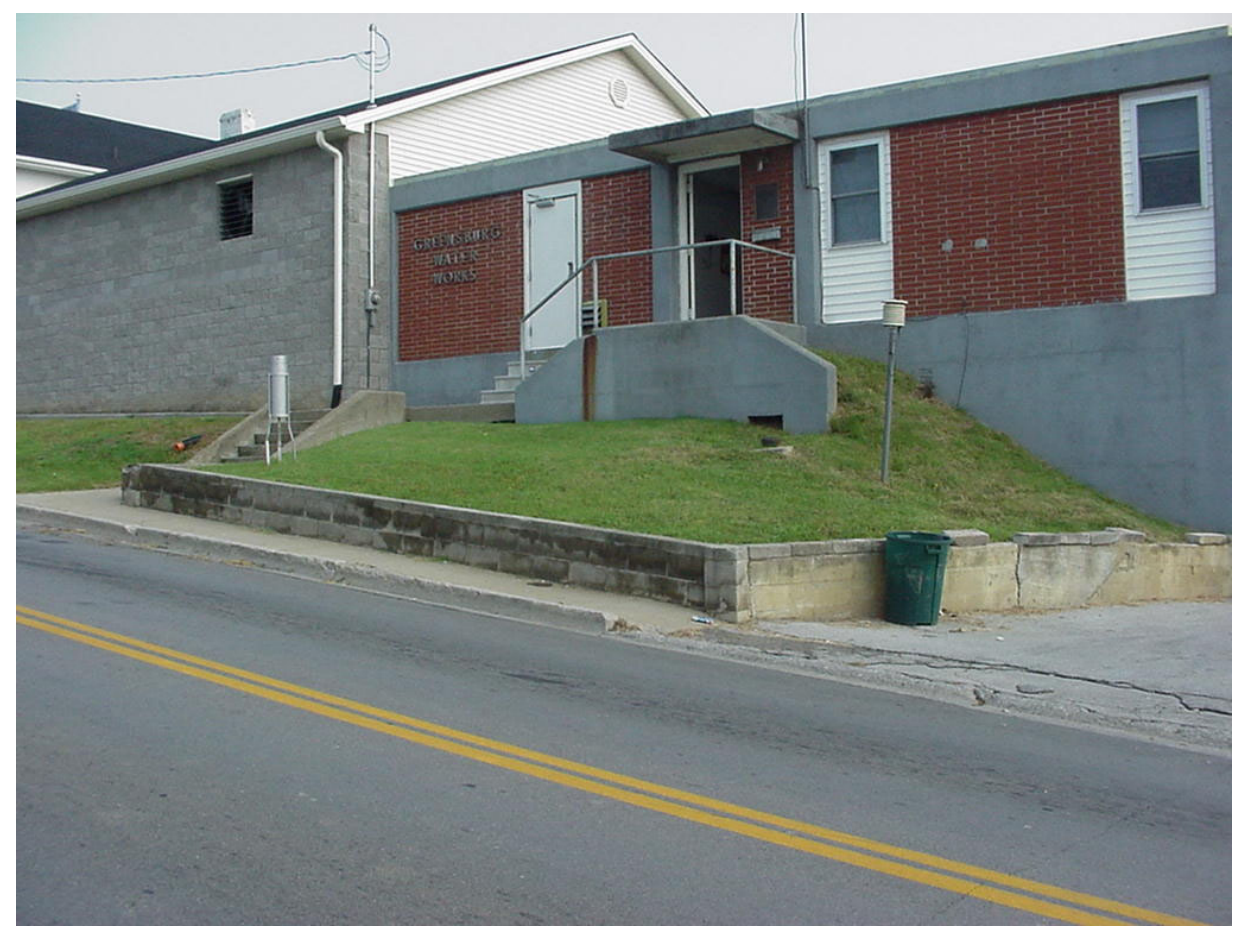

Figure 8. Same as Figure 3, except for Greensburg. This figure is available in colour online at www.interscience.wiley.com/ijoc

monthly low temperatures are consistently warmer at GRE, particularly through the summer. In addition, the average monthly maximum temperatures become slightly warmer at NRL through the warm season.

The extreme monthly maximum temperatures at NRL consistently remain higher by up to $1.9^{\circ} \mathrm{C}$ compared to the MCN site, except during the early spring months (March through April) (Figure 10(a)). The extreme monthly minimum temperatures are higher (up to $2.4^{\circ} \mathrm{C}$ ) at GRE compared to MCN for all months while the extreme monthly maximum temperatures are higher for a significant part of the year (Figure 10(b)). The analysis of data shows that the extreme monthly minimum temperature at the GRE site is consistently higher (up to $2.4^{\circ} \mathrm{C}$ ) compared to the NRL site (Figure 10(c)). On the other hand, the extreme monthly maximum temperatures are higher at the NRL station, up to $1.5^{\circ} \mathrm{C}$, for most of the year except for the winter months.

GeoProfiles, photographs, and traditional metadata suggest that the impact of radiative cooling over nearby asphalt and paved surfaces keep the monthly average minimum temperature data lower at NRL compared to MCN for most of the year (Figure 9(a)). The MCN site is the most representative on a regional scale. It is found that 100,98,94,97, 99, and 99\% of land use within 60,120, 240, 500, 1000, and $1500 \mathrm{~m}$ radius of MCN, respectively, is dominated by natural vegetation. There are no anthropogenic influences within the immediate proximity, and the exposure is not obstructed. Any moderating effect associated with the nearby forest cover is expected to be minor. In contrast, both the rural NRL and urban GRE sites have poor exposures.

Forcing of anthropogenically modified surfaces at NRL are more amplified during cool months compared to warm months. During summer months, forcing of asphalt is dominant at NRL and resulted in a higher monthly average maximum temperature compared to $\mathrm{MCN}$, which is located in a relatively 'natural' setting. Note that the monthly average maximum temperatures are warmer at MCN compared to NRL during the cool season. Thus, there is a switching of signs with seasonal changes. The GeoProfile of NRL indicates that it is located nearby the Nolin River Lake. However, impact of the lake on temperature records is not clear at this point. Nevertheless, it is apparent that even if there is a prevailing lake breeze during summer months, the impacts of the human-altered surface is sufficient to keep temperatures warmer at NRL compared to $\mathrm{MCN}$. 

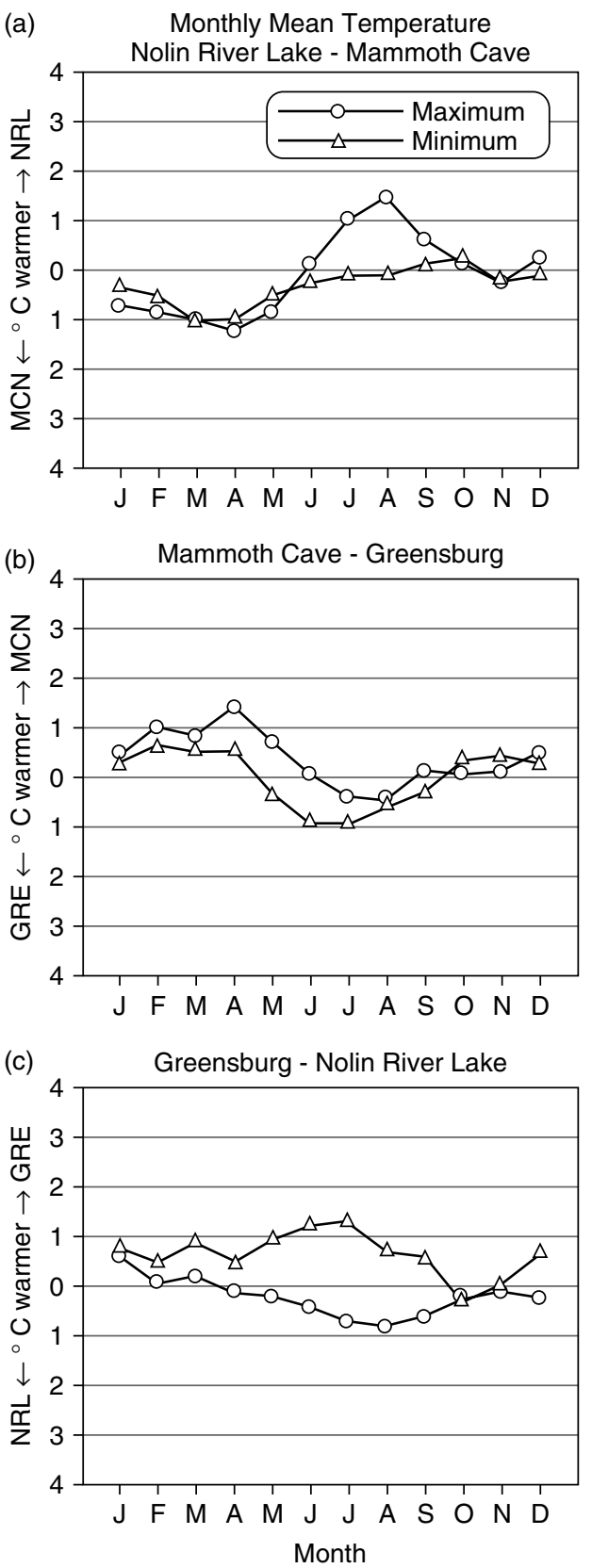

Figure 9. Same as Figure 5, except for: (a) Nolin River Lake and Mammoth Cave, (b) Mammoth Cave and Greensburg, (c) Greensburg and Nolin River Lake

Temperature patterns at GRE are consistent with the impacts of urbanization. The GeoProfile shows 100, 82, $74,47,27$, and $19 \%$ of the land area within $60,120,240,500,1000$, and 1500 m radius, respectively, of GRE are well developed. Thus, the higher monthly average maximum temperatures at GRE during summer months are expected owing to forcing by the urban landscape and nearby anthropogenic structures (Figure 8). The ESE aspect of the GRE site is not expected to be a significant factor influencing daily maximum temperatures. Warmer temperatures at MCN during the cool season, however, suggest that the radiative cooling associated with those same structures compensates for any UHI effect associated with a town of only 2400 people. 
(a)

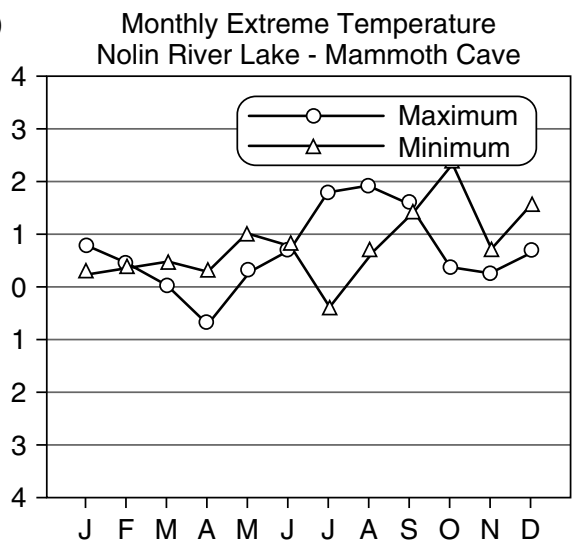

(b)

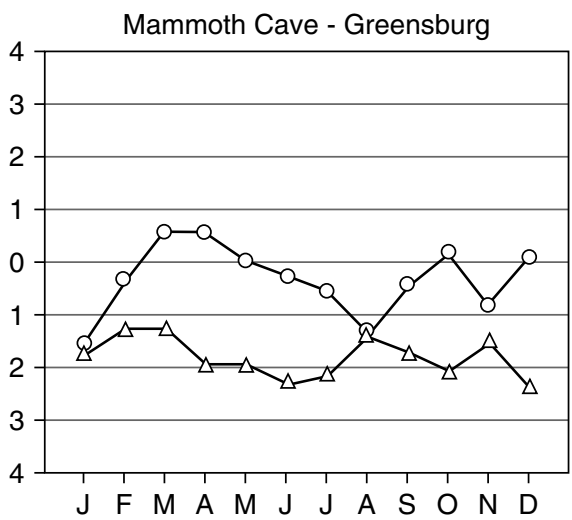

(c)

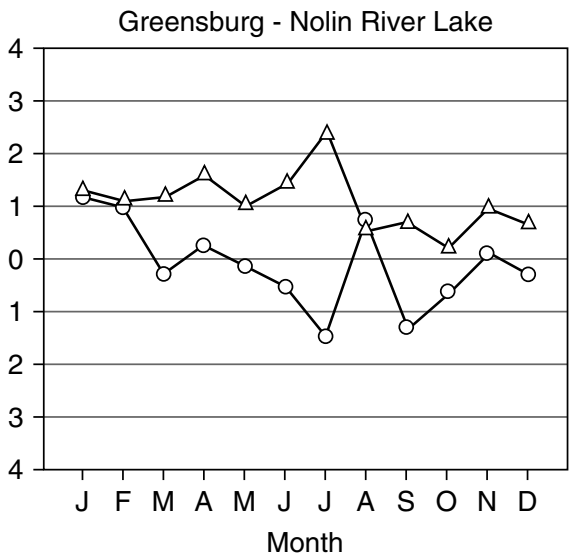

Figure 10. Same as Figure 6, except for: (a) Nolin River Lake and Mammoth Cave, (b) Mammoth Cave and Greensburg, (c) Greensburg and Nolin River Lake

Comparison of GRE with NRL is difficult because of complex forcings at both sites. The seasonal variation in monthly mean maximum temperature shows that the exposure at NRL is more sensitive to increased solar radiation during the warm season. The variation in minimum temperature is more complex and not readily explained.

As evident from the above discussion, there was no simple interpretation of the microclimate of NRL, and hence we were not confident that the site was representative of the surrounding region. Furthermore, a location change prior to the study period considered in this investigation, in which the station at NRL was 
moved only 0.1 mile up a slope, led to a $3{ }^{\circ} \mathrm{C}$ increase in the mean daily minimum temperature. The impact of the instrument exposure was thus quite severe and exceeded our expectations concerning the impact of exposure on temperature records. Given the rough terrain and varied land cover in this region, the assumption that a representative site can be found for this region is questionable.

The use of DEMs to model site topography is an important component of GeoProfiles and was very helpful in analyzing the impacts of exposure on temperature records. While many sites were located on flat surfaces, some were positioned on slopes, and the variations in slope and aspect influence the microclimate of a station. However, for the stations in group 1, the effects of slope and aspect were typically confounded with the impacts of paved surfaces and vegetation canopies, as evident at GRE, NRL, and SSH.

Forcing of asphalt on the monthly maximum temperature appears to be greater during most of the year at NRL compared to GRE, although at both these locations the instruments are exposed to a similar type of surfaces. In fact, GRE is exposed to more nearby building structures. It is noted above 100, 82, 84, and $47 \%$ of land area within $60,120,240$, and 500 m radius, respectively, of GRE is well developed. One the other hand, these statistics for NRL is $21,26,17$, and $7 \%$, respectively. The authors speculate that the darker asphalt colored parking lot may have resulted in such differences. Forcing of urban landscape and UHI is quite apparent in the monthly average minimum temperature of GRE, which resulted in higher temperatures at this site compared to NRL (Figure 9(c)). The GeoProfiles combined with traditional metadata suggest that forcing of urban land use and paved surfaces at GRE resulted in consistently higher extreme temperatures compared to nearby MCN and NRL.

\section{Group 3}

This group is composed of stations located at Beaver Dam (BEA), Leitchfield (LEI), and Rough River Lake (RRL). Both the BEA and LEI sites use temperature measuring units surrounded by mature trees and located adjacent to single-story buildings. The BEA site is in a residential area, and the topography gently slopes to a shallow bottom. The GeoProfile shows that 83, 64, 45, and 34\% of the area within 60, 120, 240, and $500 \mathrm{~m}$ radius from BEA is classified as low intensity residential area. The LEI site is located outside a radio station on the outskirts of a small town (Figures 11(a)-(e) and 12(a)-(b)). Quantitative assessment of land-use component of the GeoProfile also provides supporting evidence (not shown here). The site is flat and situated near an asphalt parking lot. In contrast to these sites, the RRL site is on a flat grassy land near a fence line that separates a lawn from a field. There are no obstructions in the vicinity of the instrument shelter.

Figures 13(a)-(c) present the differences of the mean maximum and minimum temperatures among Group 3 stations. Analysis of data shows that the mean monthly maximum temperature at RRL increases through the warm season relative to the BEA and LEI sites. Daily minimum temperatures, meanwhile, are significantly cooler throughout the year at RRL where temperatures average by about 2.6 and $3.8^{\circ} \mathrm{C}$ lower than those at LEI and BEA, respectively. The DTR at RRL remains greater (up to $3.9^{\circ} \mathrm{C}$ ) than those at both LEI and BEA year round. The comparison of BEA and LEI reveal very similar seasonal temperature patterns.

Figures 14(a)-(c) show the differences in the extreme temperatures among Group 3 stations. Analysis of data shows that the extreme monthly maximum temperature remains higher by up to $1.1^{\circ} \mathrm{C}$ for all months at BEA compared to LEI. Furthermore, this pattern also holds for the extreme monthly minimum temperature except for the late summer and fall months (Figure 14(a)). The extreme monthly maximum temperature remains consistently higher at RRL compared to BEA (up to $1.2^{\circ} \mathrm{C}$ ) and LEI (up to $2.3^{\circ} \mathrm{C}$ ) (Figure 14(b) $-(\mathrm{c}$ )). On the other hand, the extreme monthly minimum temperatures at BEA and LEI remain up to 3.6 and $2.6^{\circ} \mathrm{C}$ higher, respectively, compared to RRL (thus displaying a case of decoupling of the temperature parameters) (Figure 14(b)).

The open exposure of the RRL site contrasted with the exposures at BEA and LEI where mature trees degrade the exposure, the open exposure contributes to the higher warm season temperatures at RRL, while the tree cover and possibly UHI effects contribute to the higher minimum temperatures at BEA and LEI. Likewise, on the basis of the assumption that the extreme maximum temperatures tend to 

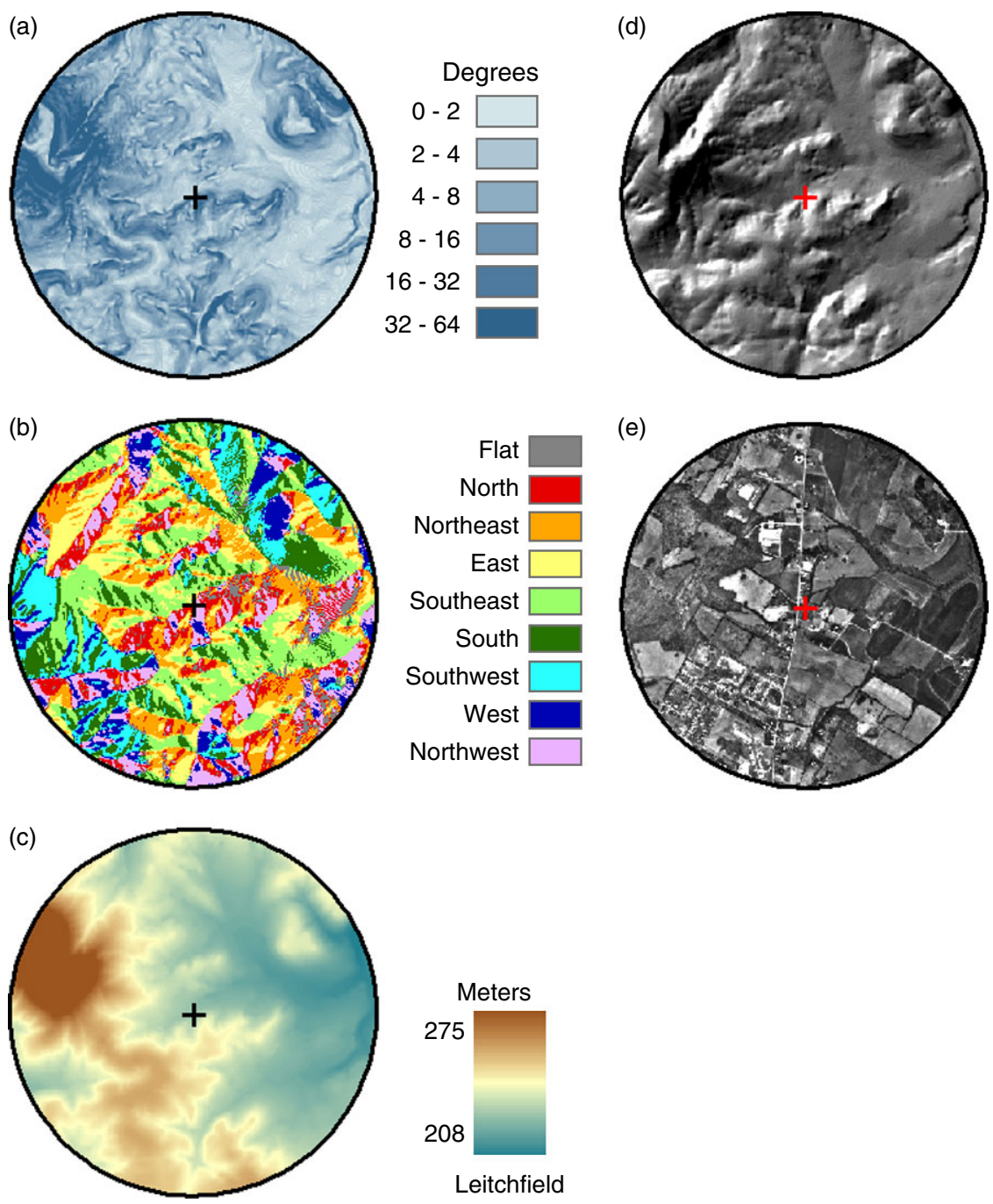

Figure 11. (a-e) Same as Figure 1, except for Leitchfield. This figure is available in colour online at www.interscience.wiley.com/ijoc

occur on sunny days, the comparatively higher monthly extreme maximum temperatures than the monthly mean maximum temperatures at RRL is consistent with the greater impact of solar radiation at this location.

\section{Group 4}

The stations included in this group are located at Henderson (HEN), Madisonville (MAD), and Providence (PRO). The HEN station is located in a rural area dominated by agricultural land use, and on grass-covered knoll with fruit trees in the vicinity. Relief is minimal in the area. The GeoProfile assessment shows that 100 , $94,97,95,92$, and $94 \%$ of the area within $60,120,240,500,1000$, and 1500 m radius, respectively, is under planted/cultivated land use. The MAD station is located in a rural setting north and east of the community of Madisonville, a city of 19300 . The instruments are located about $100 \mathrm{~m}$ south of a small reservoir used to supply drinking water to the area. The site is grass covered and flat and is located near paved surfaces and a few meters above the level of the reservoir. The PRO station is in the central area of a small town with a population of 3600 and located on rolling terrain (Figures 15(a)-(e); 16(a)-(b)). The instrument shelter is located near a street on a narrow, grass-covered strip between two asphalt parking areas. The GeoProfile 
(a)

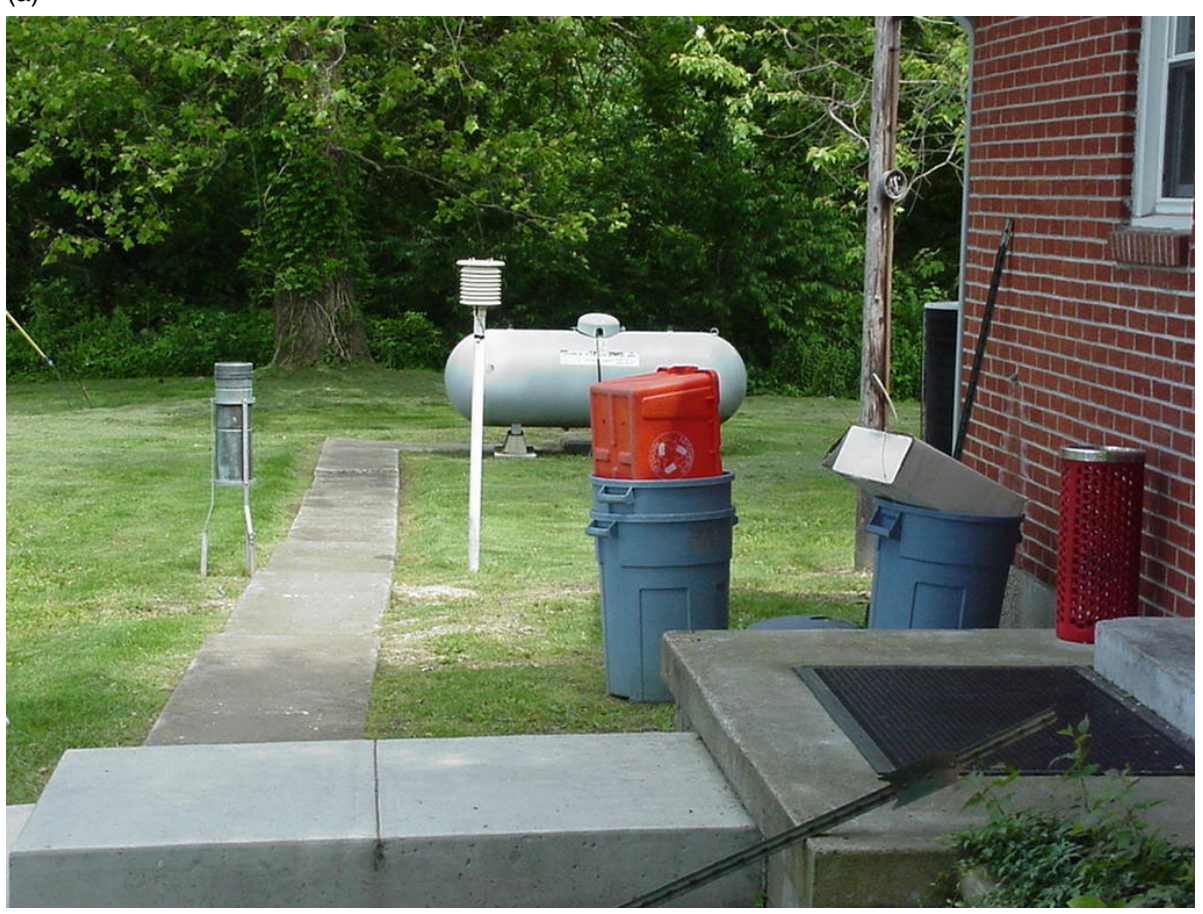

(b)

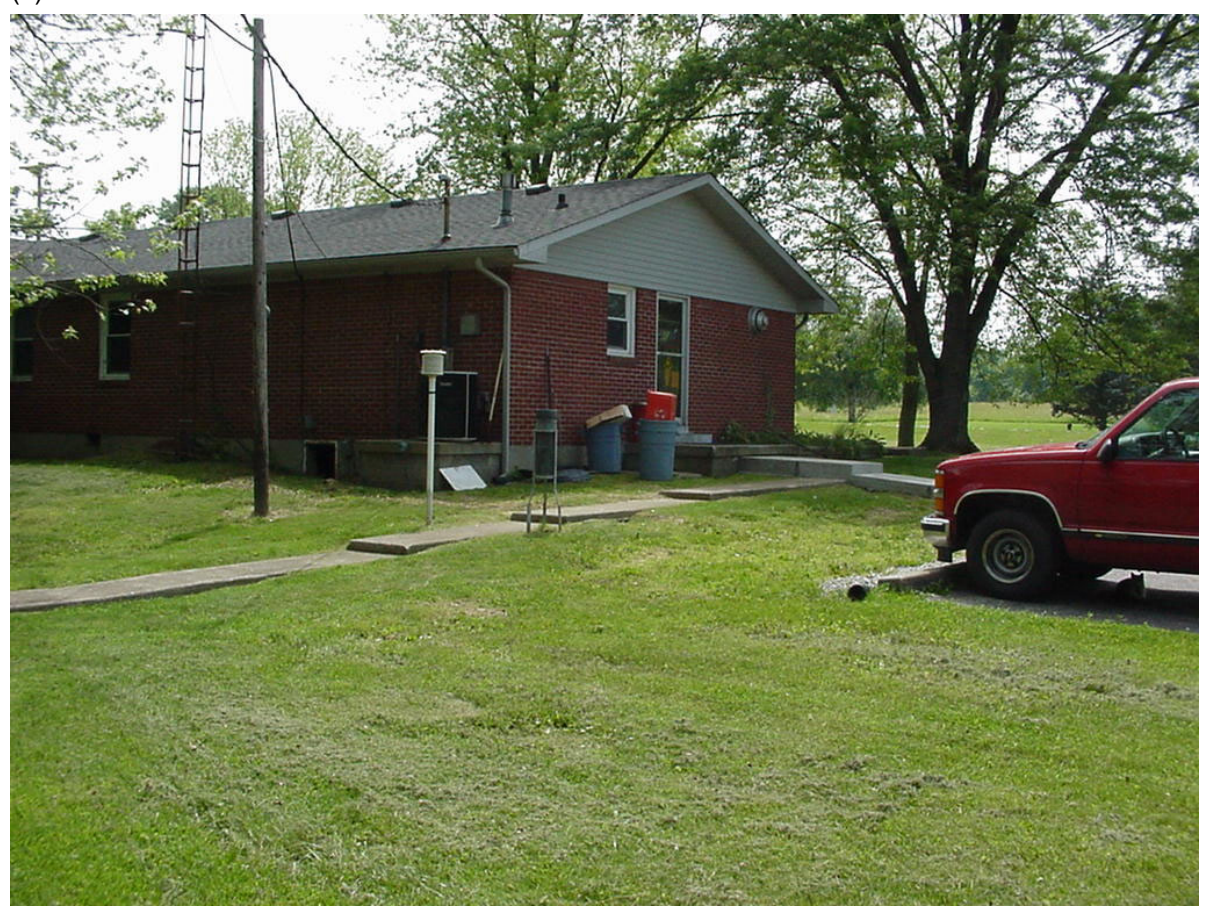

Figure 12. (a-b) Same as Figure 3, except for Leitchfield. This figure is available in colour online at www.interscience.wiley.com/ijoc

suggests that $39,38,47,64,58$, and $44 \%$ of the area within $60,120,240,500,1000$, and $1500 \mathrm{~m}$ radius, respectively, of PRO is developed. 

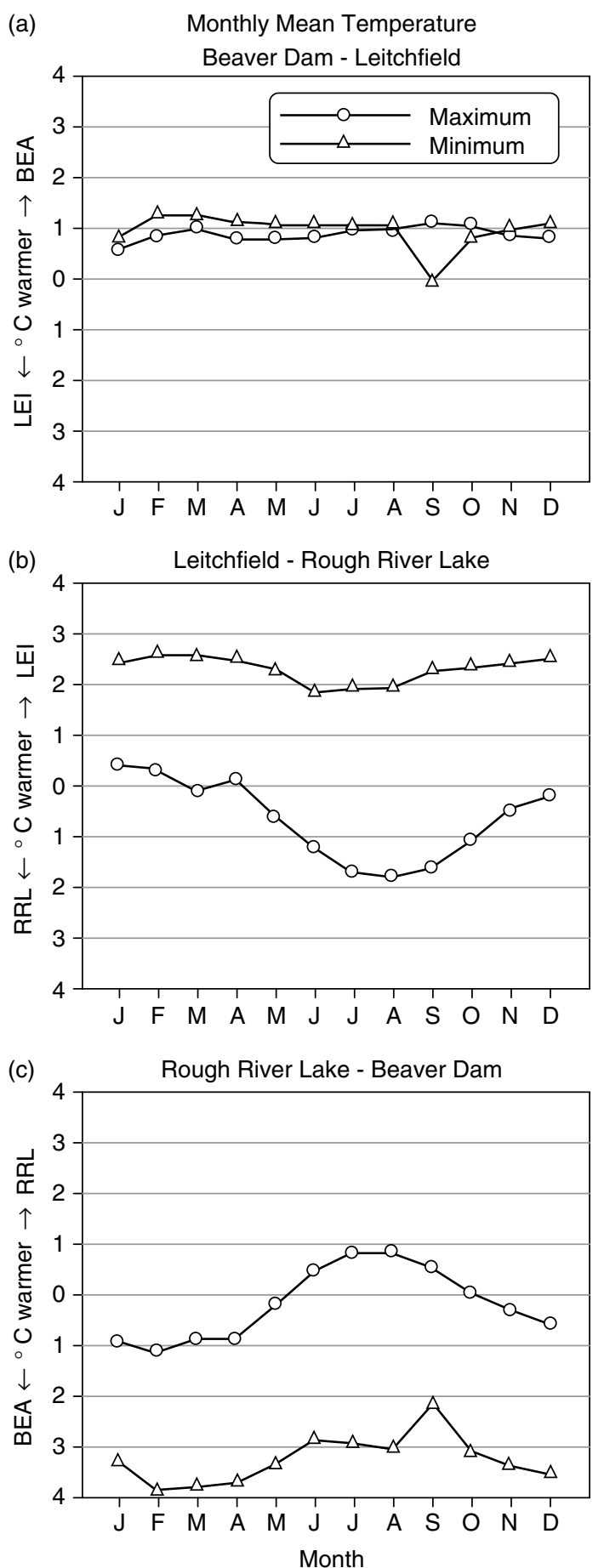

Figure 13. Same as Figure 5, except for: (a) Beaver Dam and Leitchfield, (b) Leitchfield and Rough River Lake, (c) Rough River Lake and Beaver Dam

Analysis of temperature data shows that the warm season average monthly maximum and minimum temperatures are slightly higher at PRO compared to HEN and MAD (Figure 17(a)-(c)). The cool season monthly average maximum and minimum temperatures are up to $0.7^{\circ} \mathrm{C}$ warmer for both parameters at MAD 
(a) Monthly Extreme Temperature

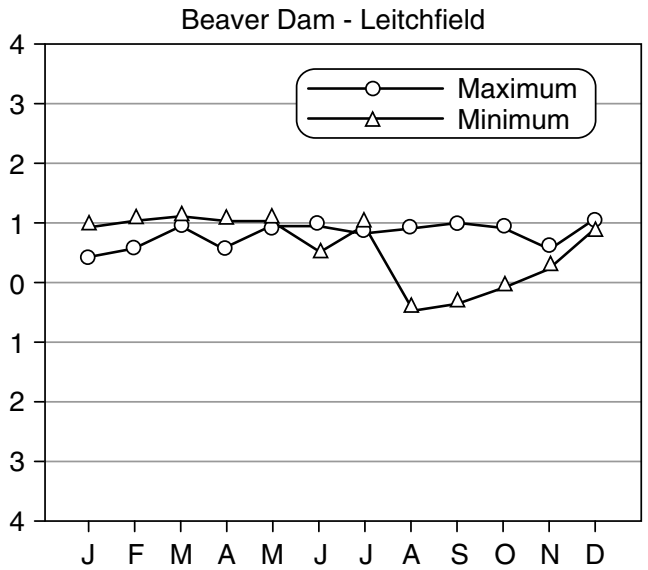

(b)

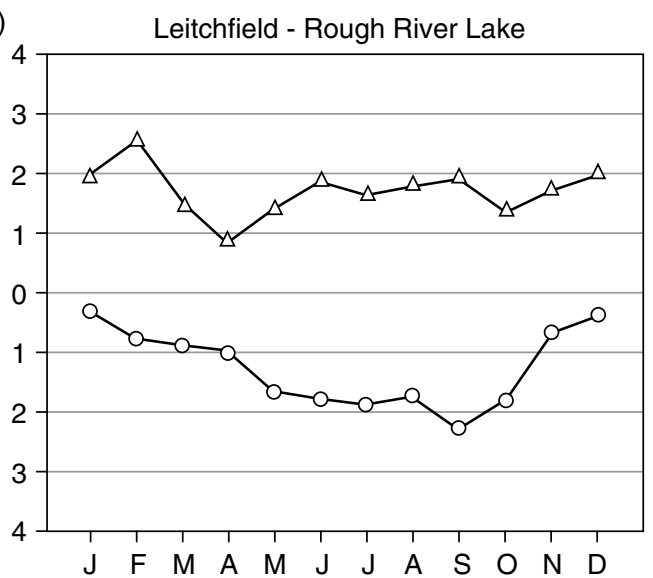

(c)

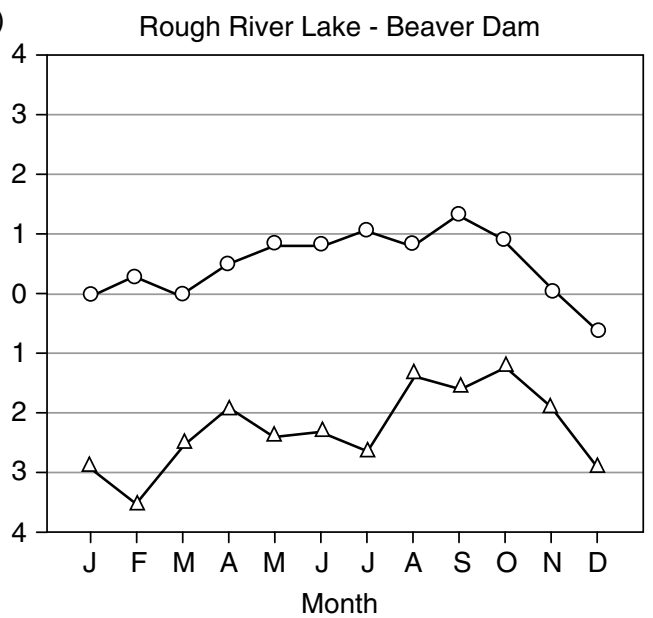

Figure 14. Same as Figure 6, except for: (a) Beaver Dam and Leitchfield, (b) Leitchfield and Rough River Lake, (c) Rough River Lake and Beaver Dam

compared to PRO (Figure 17(b)). At HEN, the average monthly maximum temperatures are relatively warmer during the cool season (January through March). The comparison between the rural sites at HEN and MAD 

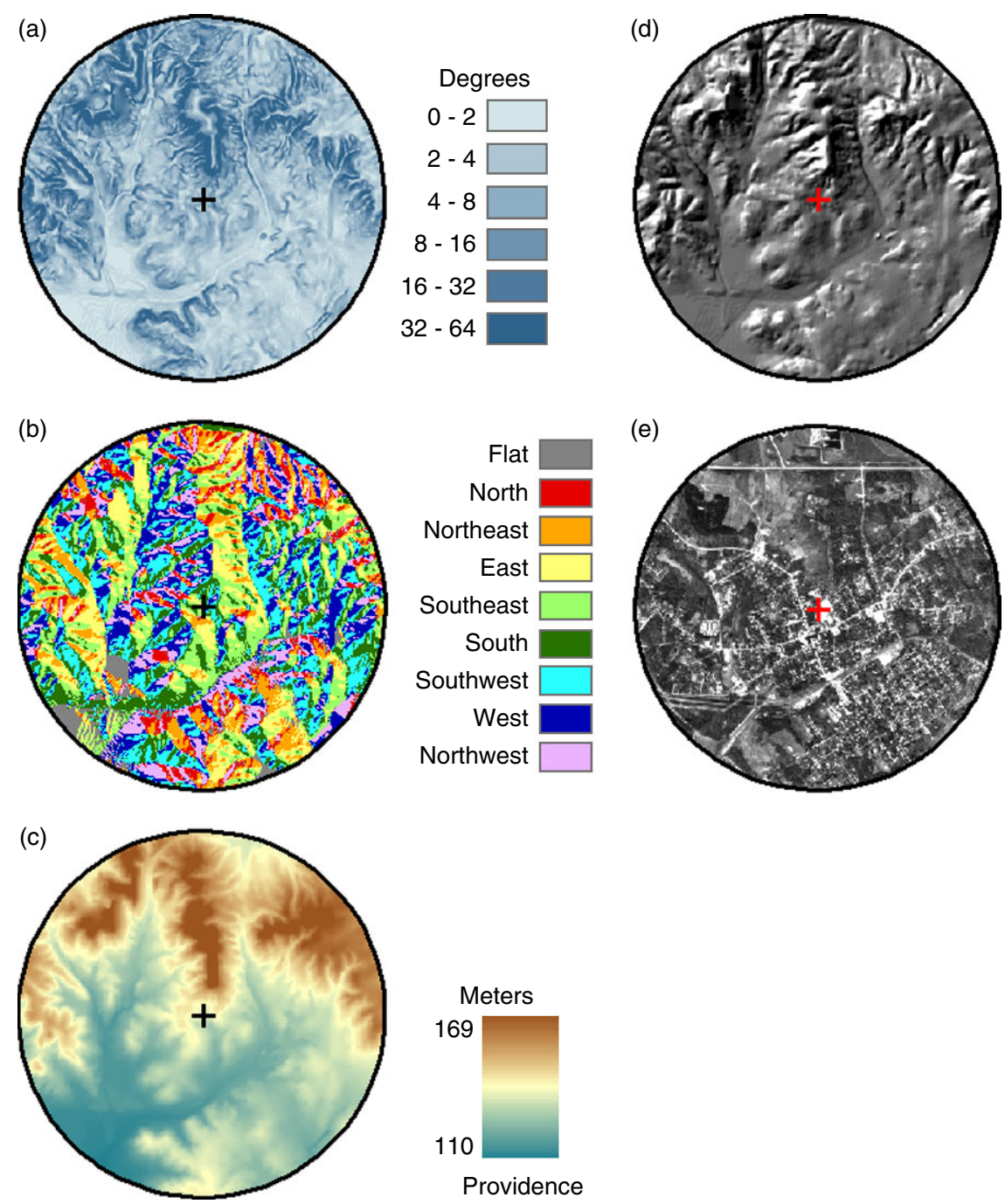

Figure 15. (a-e) Same as Figure 1, except for Providence. This figure is available in colour online at www.interscience.wiley.com/ijoc

show no particular seasonal pattern (Figure 17(c)). Moreover, cool season assessment of DTR shows that it remains 1.3 and $1{ }^{\circ} \mathrm{C}$ higher in PRO and MAD, respectively, compared to HEN.

The monthly maximum and minimum extreme temperatures at PRO are up to 2.4 and $1.6^{\circ} \mathrm{C}$ higher, respectively, compared to HEN for all months (Figure 18(a)). Compared to MAD, the extreme monthly maximum temperatures at PRO remain up to $0.8^{\circ} \mathrm{C}$ higher during the warm season, while the opposite is true during the cool season (up to $1.1^{\circ} \mathrm{C}$ lower) (Figure 18(b)). In addition, analysis demonstrates that compared to HEN, the extreme monthly maximum and minimum temperatures are consistently higher by up to 1.7 and $1.1{ }^{\circ} \mathrm{C}$, respectively, at MAD (Figure 18(c)). Furthermore, records demonstrate that the monthly extreme minimum temperatures are higher at PRO compared to MAD for most of the year. During summer months, the forcing of urban land use on average temperatures is evident in case of PRO. However, the signal is not so clear during cool months. Among this group of stations, the rural HEN station has the most desirable exposure. While the MAD site is more complex, temperatures at MAD show a similar pattern of seasonal variation to those at HEN. Though temperatures remain slightly warmer at MAD, they suggest that the nearby reservoir is not a factor at that site. Likewise, our site visit combined with analysis of ortho photos suggested that the station was sufficiently distant from the city of Madisonville to negate concerns 
(a)

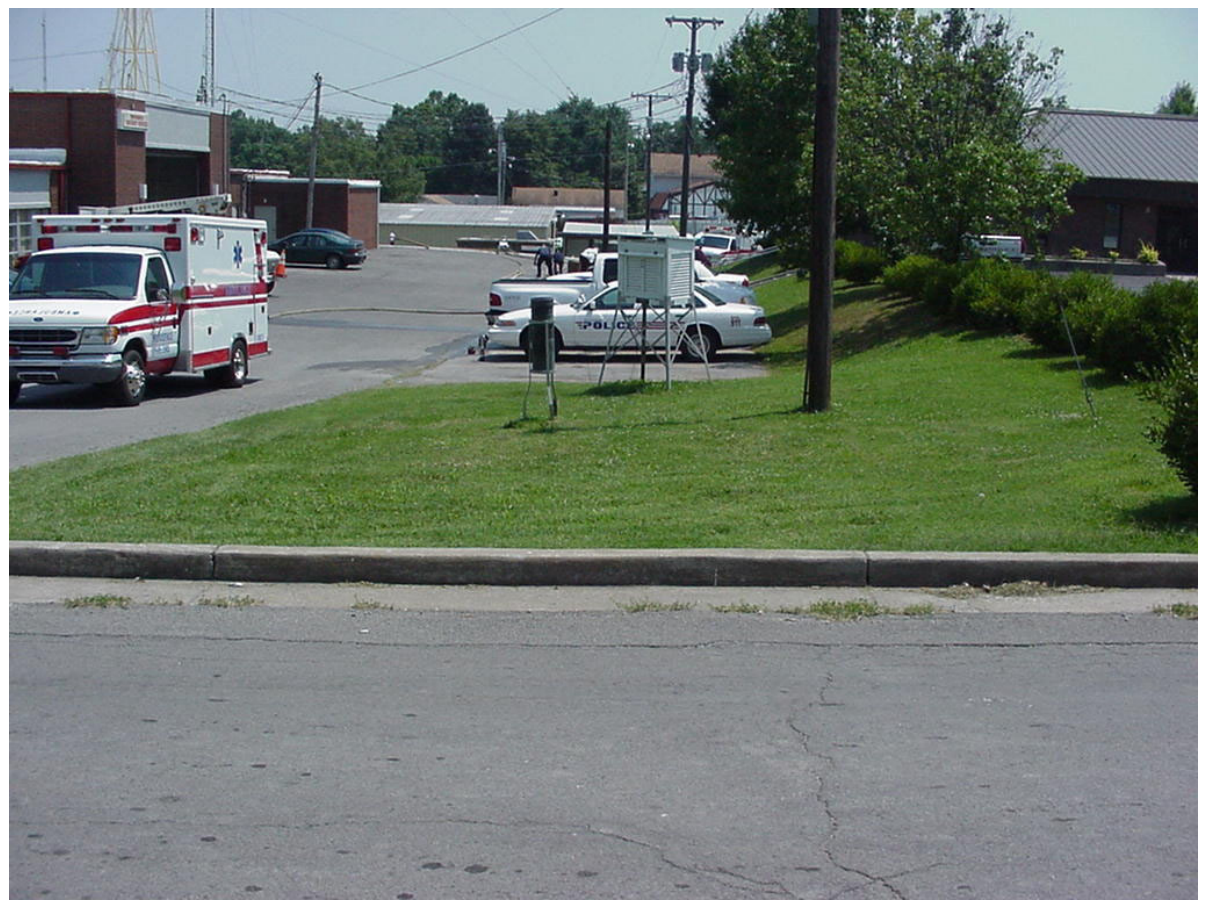

(b)

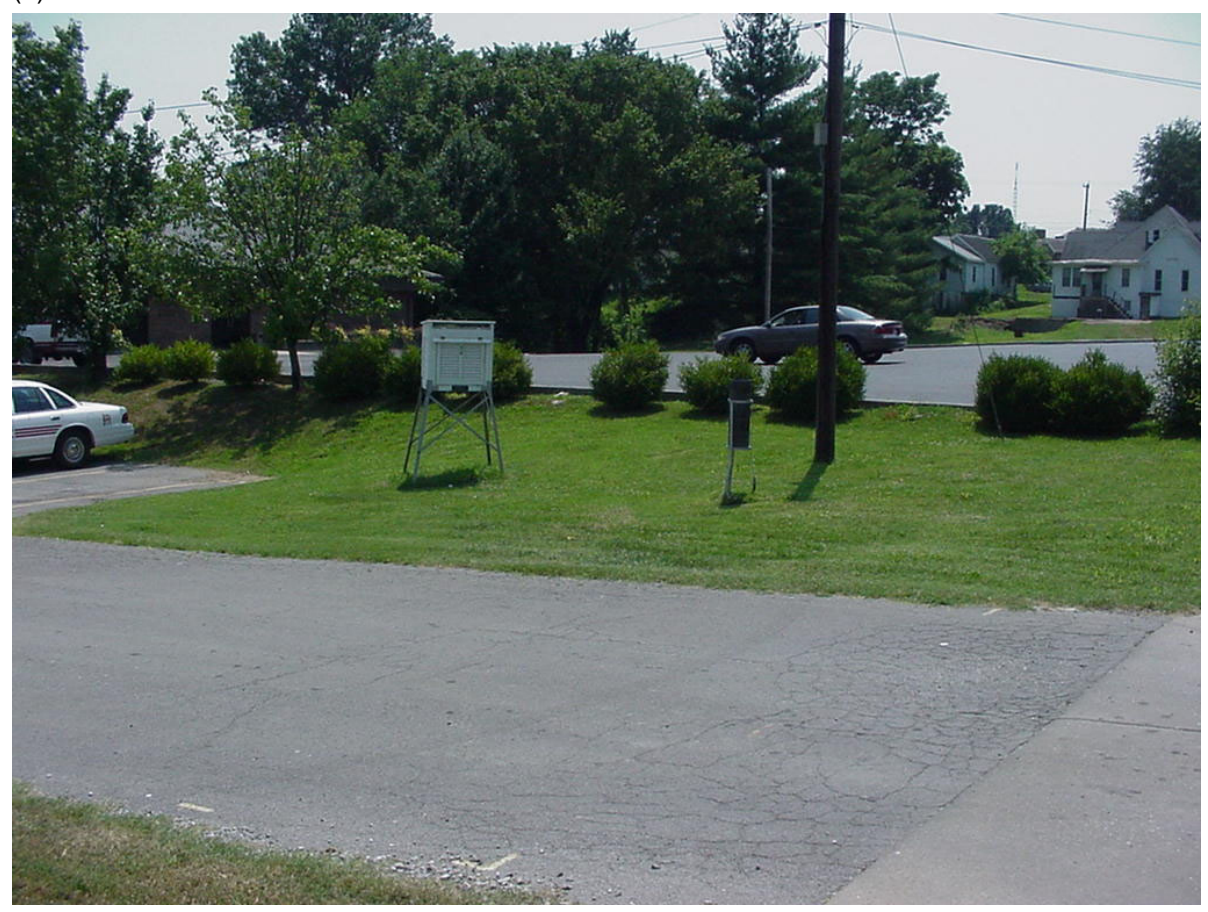

Figure 16. (a-b) Same as Figure 3, except for Providence. This figure is available in colour online at www.interscience.wiley.com/ijoc

with UHI forcing. Meanwhile, the PRO station located near the center of the town of Providence has the least desirable exposure. Temperature comparisons involving PRO show evidence of urbanization effects. 

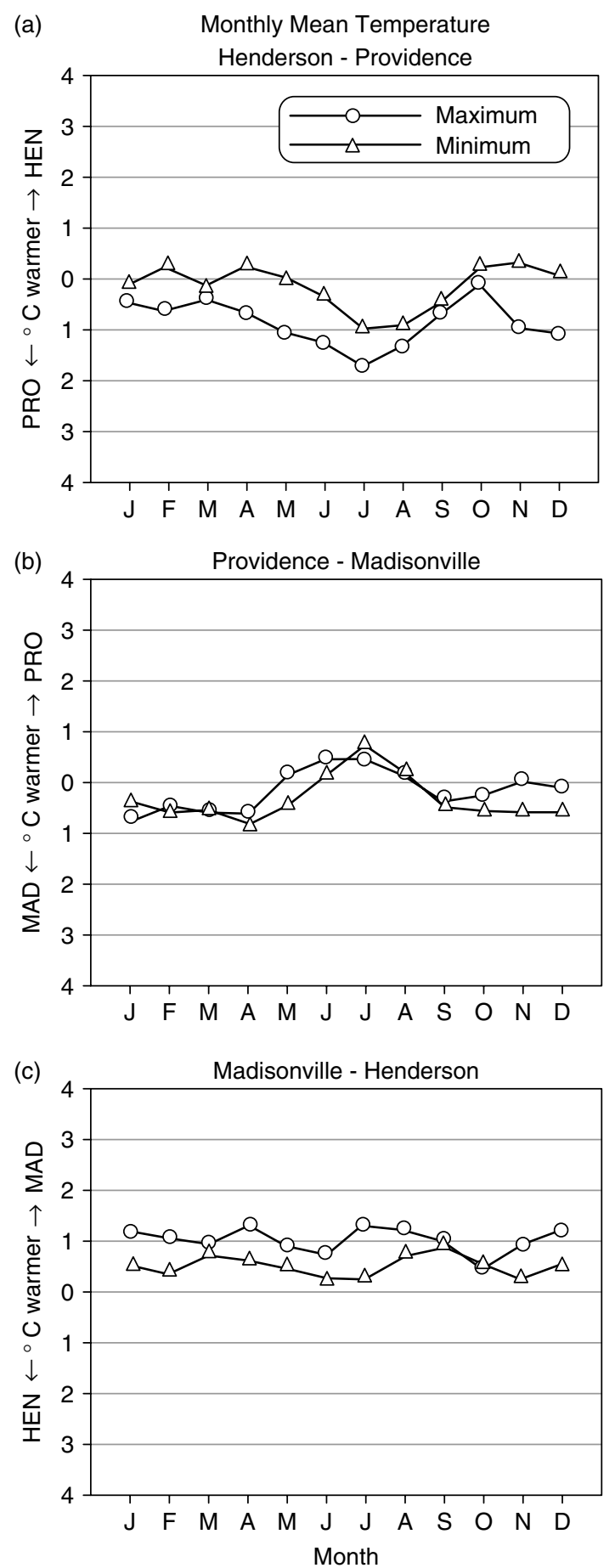

Figure 17. Same as Figure 5, except for: (a) Henderson and Providence, (b) Providence and Madisonville, (c) Madisonville and Henderson

The asphalt surfaces and brick buildings in close proximity to the station contribute to an increase in both maximum and minimum temperatures at PRO relative to HEN and MAD during the warm season. Land-use estimates (provided above) from the GeoProfile suggest that the developed areas around PRO offer micro- 
(a) Monthly Extreme Temperature

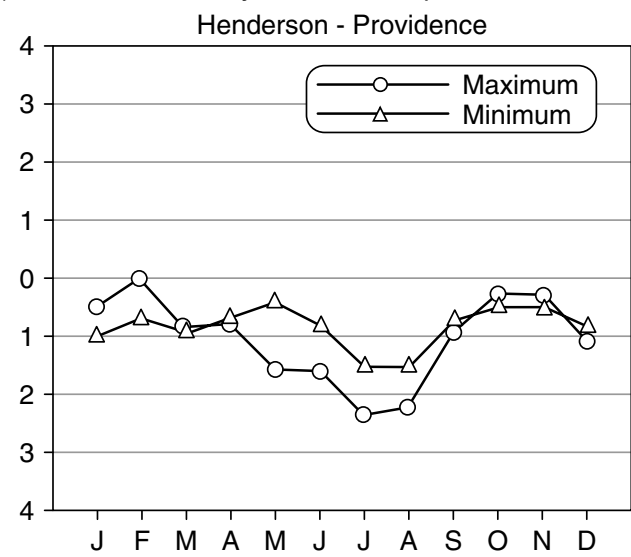

(b)

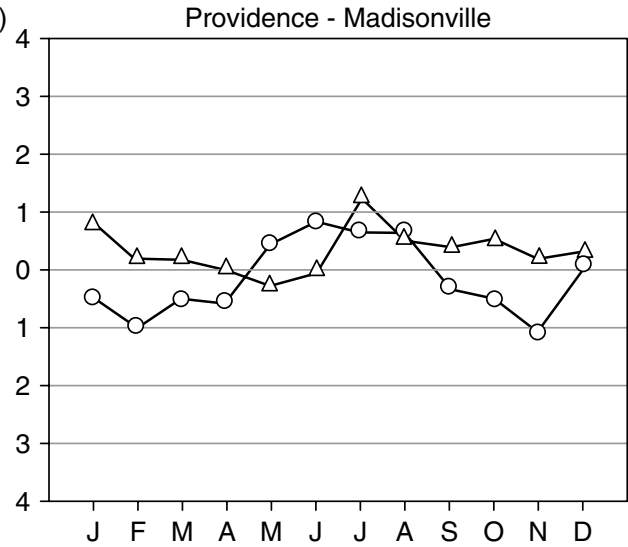

(c)

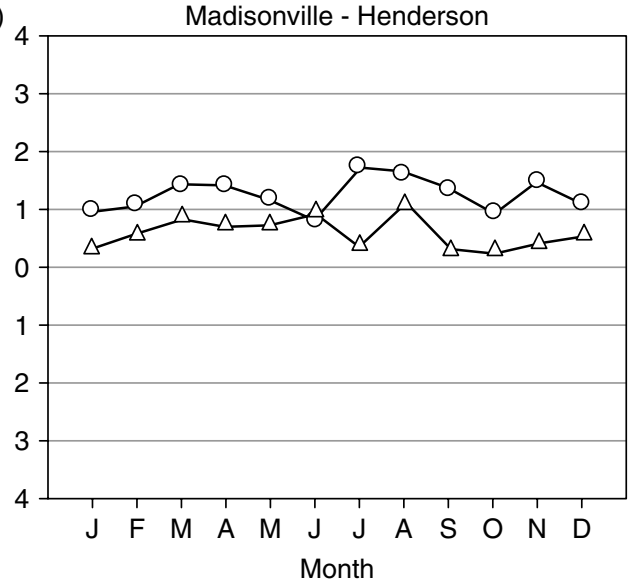

Figure 18. Same as Figure 6, except for: (a) Henderson and Providence, (b) Providence and Madisonville, (c) Madisonville and Henderson

and meso-scale forcing that affect these differences. While the monthly extreme minimum temperatures tend to be comparatively higher at PRO, monthly mean minimum temperatures do not follow this pattern.

In summary, on the basis of visits to the 12 COOP sites, it is found that there is an alarming variety of natural and anthropogenic features that affected instrument exposures. Most of these features were in 
immediate proximity to the instruments. The most common problems were associated with paved surfaces and vegetation canopies. As noted previously, the nature of UHIs has been widely explored, particularly for larger metropolitan areas. Several of the stations we used were located in or near small towns ranging in population from more than 2000 to nearly 20000 . Our analyses produced some results that were consistent with the expected impacts of urbanization; however, anthropogenic biases in the temperature records for these small towns appeared to have more to do with the immediate site of the instrument exposure. In site comparisons that involved stations with asphalt pavement in close proximity to the instrument shelter or sensor unit, the temperature comparisons showed patterns of variation that were coherent with the expected impacts of such surfaces - higher temperatures during the warm season and lower temperatures during the cool season. In cases where the stations were situated near asphalt in urban areas, data suggested that the influence of the proximate surfaces was much greater than any UHI effect. Furthermore, the temperature records from some of the rural sites - BRL and NRL - were consistent with the expected influence of proximate paved surfaces.

\section{EXPOSURE OF INSTRUMENTS AND ANALYSIS OF ANNUAL TEMPERATURE DATA}

Analyses presented here highlight the patterns in annual temperature averages over the period 1991 through 2000. In cases where a station was relocated, data from before and after the relocation are included, so it is possible to assess the impact of the station relocation. The ability to identify and interpret patterns in the annual data is difficult for two reasons. First, the time span is arguably too short to establish evidence of stable, long-term trends. Second, there is little direct information about changes in the exposures at the various stations. While we looked at the available NWS station history forms, they did not always provide sufficient information about changes to exposures. In other cases, it is suspected that changes in land cover or surfaces in the vicinity of a station were simply not documented. Note, however, that our purpose is to investigate the need for improved metadata by documenting variability in temperature records over a period short enough that the station exposures should be nearly stationary. If the data show sufficient variation over a 10-year period, then concern is heightened about the ability to interpret temperature variations over longer time spans.

\section{Group 1}

Two patterns are evident for this group, and a third is suggested by the data. First, daily minimum temperatures and, to a lesser extent, daily maximum temperatures increase at GLW compared to both BRL and SSH after 1993 (Figure 19(a)-(b)). This change can be attributed to a change in the location of the GLW station as documented in a NWS Form B-44. The station was moved a half mile in the late 1993 to a 'compatible location.' A more interesting pattern is evident in comparisons involving the SSH station. The daily minimum temperatures are initially about $1.0^{\circ} \mathrm{C}$ warmer at $\mathrm{SSH}$ than at BRL, but show a cooling through 1997. By that time, BRL has become $1.0^{\circ} \mathrm{C}$ warmer (Figure 19(b)). The pattern then shifts as minimum temperatures start to increase again at SSH relative to BRL. The same pattern is evident in comparing SSH with GLW, though it is noisier due to the station location change at GLW (Figure 19(c)). Finally, though daily maximum temperatures tend to be more stable, there appears to be a step change representing an approximate increase of about $0.5^{\circ} \mathrm{C}$ at BRL in 1996 relative to SSH and GLW.

\section{Group 2}

The effects of two station relocations dominate annual variations in this group. First, the station at NRL was moved about 0.1 mile north to improve the exposure in late 1993. The result of the move cannot be readily detected by examining the daily maximum temperatures. However, the daily minimum temperatures at NRL increase approximately $3.0^{\circ} \mathrm{C}$ as a result of the move (Figure 20(a)-(c)). Second, the COOP station at MCN ceased its operations in 1999, and observations were then used from a remote automated weather station (RAWS) a few kilometers removed. This move again had a greater impact on the daily minimum temperatures, but an impact on the maximum temperatures is also evident (Figure 20(b)). 

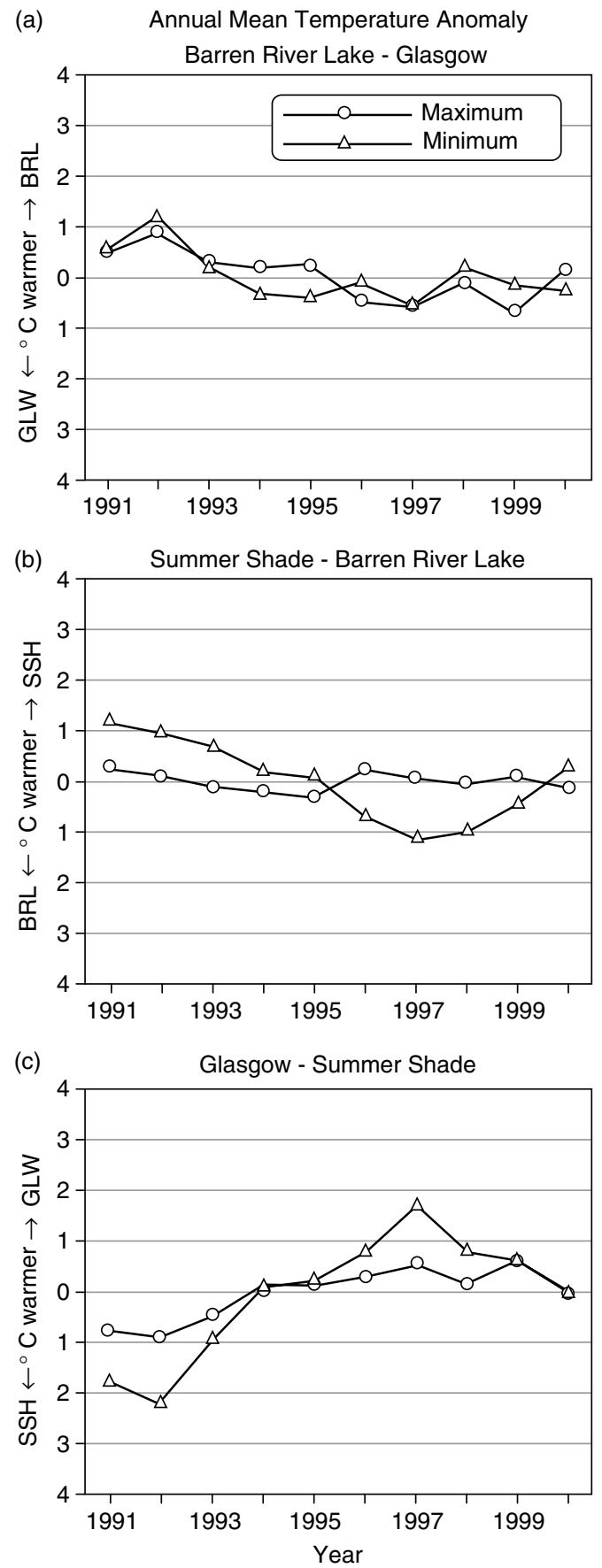

Figure 19. (a-c) Same as Figure 5, except for annual mean maximum and minimum temperature

\section{Group 3}

This group of stations shows no strong evidence of systematic patterns over the 10-year period (Figure 21(a)-(c)). There is some indication of a relative cooling in the daily minimum temperature at RRL compared with LEI and BEA in the last two years of the study period; however, the number of data points is not sufficient to define a pattern. 

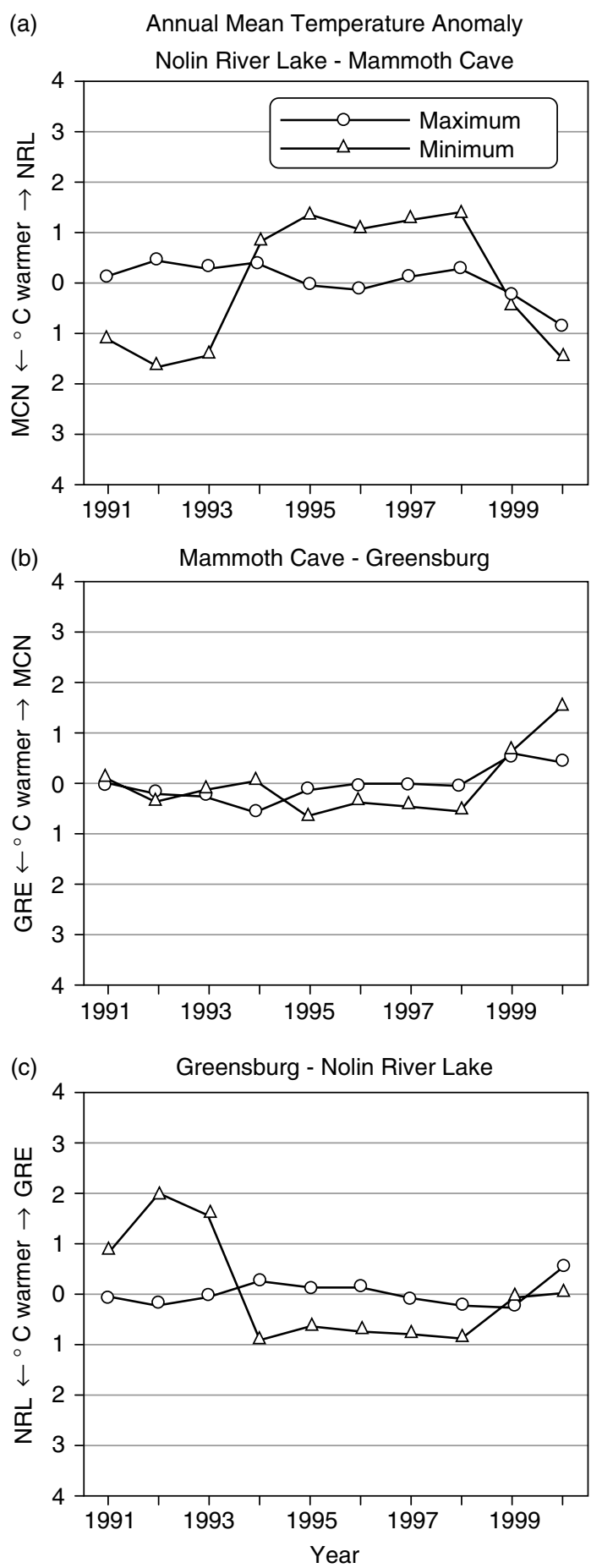

Figure 20. $(\mathrm{a}-\mathrm{c})$ Same as Figure 9, except for annual mean maximum and minimum temperature

\section{Group 4}

The final group of stations shows evidence of a step change (Figure 22(a)-(c)). Both the daily maximum and minimum temperatures decrease at PRO relative to HEN, with a change in the minimum temperatures of 
(a) Annual Mean Temperature Anomaly

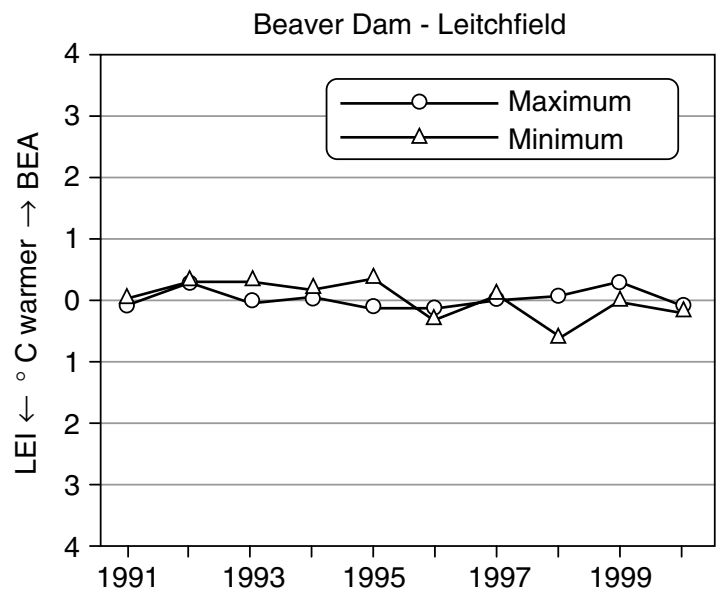

(b) 4 Leitchfield - Rough River Lake

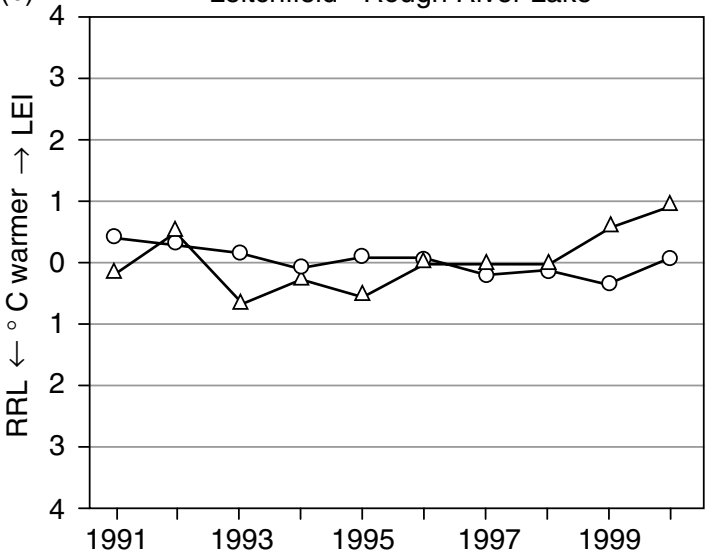

(c) Rough River Lake - Beaver Dam

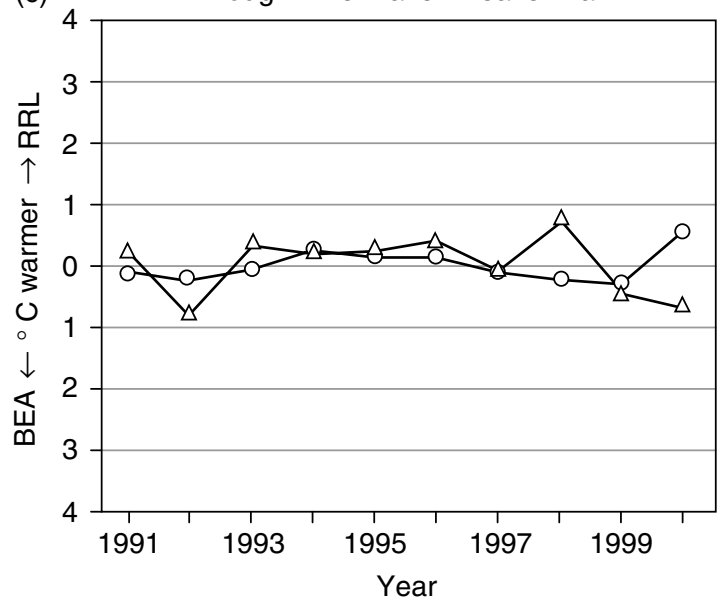

Figure 21. $(\mathrm{a}-\mathrm{c})$ Same as Figure 13, except for annual mean maximum and minimum temperature

about $1.0^{\circ} \mathrm{C}$. Likewise, temperatures decrease at PRO relative to MAD. However, in this case the decrease in the daily minimum temperatures is more than $2.0^{\circ} \mathrm{C}$, whereas the daily maximum temperatures decrease 
(a) Annual Mean Temperature Anomaly
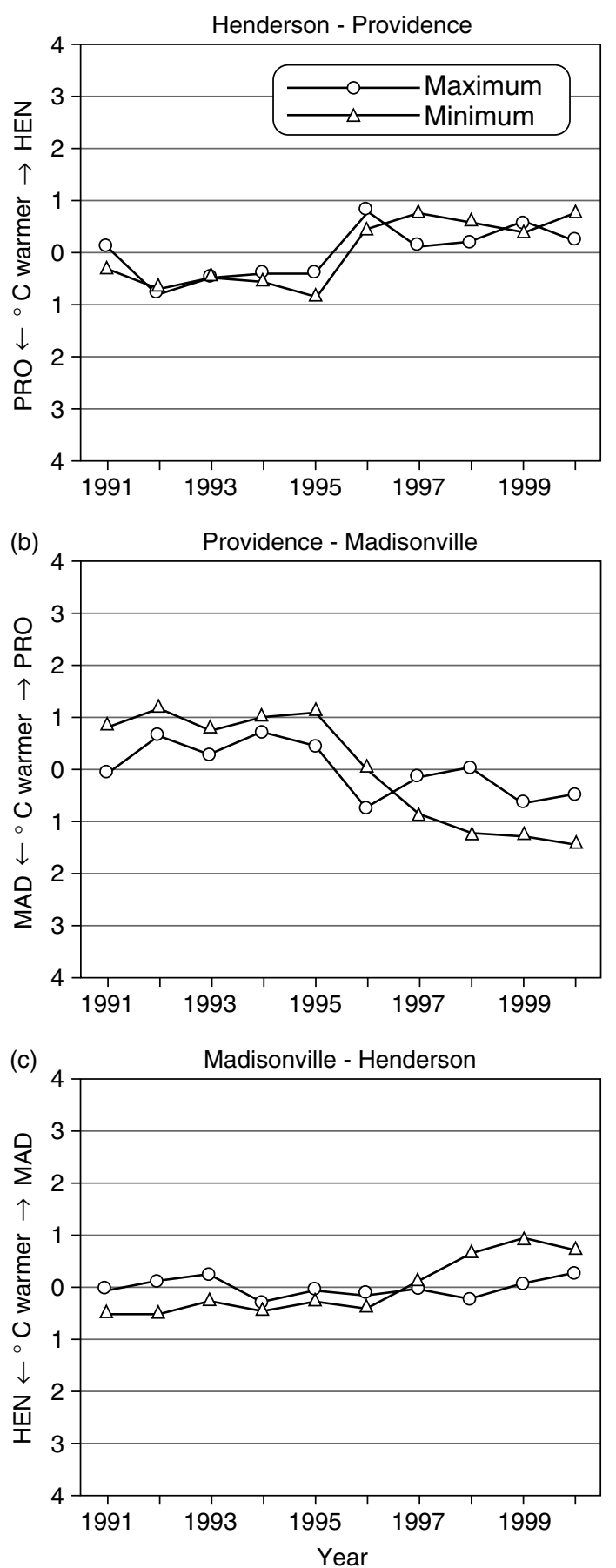

Figure 22. $(\mathrm{a}-\mathrm{c})$ Same as Figure 17, except for annual mean maximum and minimum temperature

by about $1.0^{\circ} \mathrm{C}$. These changes in the daily minimum temperatures appear to reflect a change at MAD, as the comparison between MAD and HEN also show a relative increase in the daily minimum temperatures in 1998. 
As noted above, we chose to investigate the temperature records over a 10 -year period. It was felt that given a short time period, there would be fewer station moves and the exposures would change little, resulting in stable temperature comparisons. What this study found was alarming. While a few of the comparisons did show stable patterns, many others did not. Worse yet, some of the patterns were quite complex and not readily explainable. Of particular interest were comparisons involving the SSH, BRL, and GLW stations. SSH showed an initial cooling relative to BRL and GLW, which later reversed and became relatively warmer. Given that the pattern was smooth, the forcing conditions do not seem to be associated with any particular one-time event. Other station comparisons showed evidence of a step change in relative temperatures. These changes would logically be associated with a specific event such as a change in instrumentation or improvements made to the exposure. Unfortunately, examination of available metadata frequently did not provide an explanation. On the basis of our site visits and subsequent analysis of temperature records, we suspect that the changes made to an exposure often go undocumented. For example, repaving a street, resealing an asphalt parking lot, or constructing a new building nearby might impact subsequent temperature records. Gallo et al. (1996) already reported that any changes even as far away as $10000 \mathrm{~m}$ may result in biased temperature records.

Finally, the analysis of annual data indicated that daily minimum temperatures tended to be more variable over time than daily maximum temperatures. Since daily minimum temperatures are more likely to be observed in the early morning hours before solar radiation triggers mixing in the boundary layer, we suggest that they are more sensitive to conditions within the immediate proximity of the instrument exposure. As noted throughout this analysis, only a few sites were not plagued by poor exposures. Therefore, it would be prudent to identify and interpret long-term variations in minimum temperatures only with high-quality metadata. Again, GeoProfiles presented in this paper could be an excellent tool to address this issue.

\section{IMPLICATIONS OF THE RESULTS AND CONCLUDING REMARKS}

The GeoProfile presented in this study demonstrate a new approach to archive, visualize, and communicate climatological station metadata. We suggest that this approach needs to be adopted nationally and internationally for all meteorological networks. GeoProfiles significantly enhance the currently available metadata about the micro- and meso-scale natural and anthropogenic setting of observing stations. Using a GIS platform, GeoProfiles provide visual and quantitative summaries of land use and topography at these scales. GeoProfiles then allow us to assess the potential impacts of station location on temperature measurement bias and generally provide for a more accurate assessment of records.

In an ideal setting, a well sited station results in recorded temperature values that are free of bias and representative of the broader region. However, the presence of bias in temperature observations has long been recognized. While troublesome, it is still possible to analyze climate variability and assess climate change if the site and locality of a station remain unchanged, and the bias is stationary over time. Collectively, our analyses of temperature data from 12 COOP stations (including two that are part of the USHCN) show complex patterns of pairwise temperature variability and suggest the influence of multiple sources of bias that are nonstationary over different timescales.

Evidence of bias can be found in temperature records from both urban and rural sites. All of the urbanbased stations in this study are located in towns and cities ranging in population from just over 2000 to nearly 20000 . Certainly, the small scale of urbanization limits the traditional UHI bias. However, research in urban micrometeorology (Arnfield, 2003) identifying the impacts of diverse surfaces on energy budgets, energy exchanges, and small-scale advection suggests that even a limited urbanization is relevant when examining the potential impacts of the site and locality characteristics of instrument exposures on temperature observations. While rural settings are generally considered to provide superior settings for climate observations, our research reveals that the micro-environments of rural stations are often similar to those of urban stations. Specifically, they are often characterized by the presence of paved surfaces and brick and block buildings in close proximity to instrument installations. In some cases, superior sites are available nearby.

Patterns of temperature bias often reflect seasonal variability. Several factors can play a role in this variability. A dominant influence relates to proximate deciduous vegetation canopies. The seasonal variability 
of pairwise temperatures among BEA, LEI, and RRL highlight this bias. A related factor is proximity to paved surfaces where altered surface characteristics, including albedo, exaggerate high and low temperatures, respectively, during the warm and cool seasons. Obviously, both of these influences are impacted by seasonal variations in the angle of incidence of solar radiation. Further, seasonality can also affect mean maximum and minimum temperatures differently. In the comparison of GLW and SSH, the mean monthly temperature remains warmer at the urban GLW site throughout the year, with little seasonal variation. However, the DTR, which is greater at the rural SSH site during the cool season, becomes larger at GLW during the warm season.

In addition, our analysis shows that the general notion of 'urban warming' does not always hold for all timescales. For example, BRL is a rural site and GLW is located in an urban area; however, forcing of nearby pavement is stronger at BRL compared to GLW. This is manifested in higher monthly average minimum temperatures and nearly identical monthly average maximum temperatures. As a result, BRL observes, compared to GLW, higher monthly average temperatures during the warm season. Several recent assessments of the impact of UHIs on in situ temperature observations (Peterson, 2003, for the contiguous USA) and on large-scale and long-term temperature trends (Parker, 2004, for the globe) found no significant impact of urbanization on annual temperatures (e.g. Jones and Moberg, 2003, on global temperature reconstruction and analysis). Our findings and results of these studies call for additional investigations on station exposures and bias adjustments.

Indications of similar potential bias can be found in our analysis of data from LEI and GRE and their nearby stations. Both these stations are part of the USHCN. It is found that the extreme monthly maximum temperatures are consistently higher at rural RRL compared to the nearby urban LEI location. Both these locations are exposed to pavements and other undesired structures. LEI is exposed to a brick building (within $10 \mathrm{~m}$ ). The instrument at GRE is located in front of the Greensburg water works building and a major asphalt road. These structures are potential sources of biased records. Moreover, the GeoProfile shows that 100, $82,84,47,27$, and $19 \%$ of the land area within $60,120,240,500,1000$, and $1500 \mathrm{~m}$ radius, respectively, of GRE is well developed. GeoProfiles permitted, among others, the assessment of potential forcing of topography on temperature records. For example, we have found that the draining of colder air forced by sloping topography results in a consistently lower minimum temperature in certain locations (not shown here). Hence, GeoProfiles allowed us to consider forcings of both meso- and micro-environments simultaneously. It is certainly an improvement over traditional station metadata. Evidence of bias in temperature observations and its variability over different timescales has broad research implications regarding climate variability, change, and prediction. Pielke et al. (2000, 2002a,b) examined a multidecadal time series of high and low temperatures and found conflicting trends involving stations located within the same region of eastern Colorado. To some extent, long-term temperature trends were consistent with regional land-use changes; however, unknown localized influences were acknowledged.

Our research focused on a much shorter time span. We also examined the annual variability of pairwise temperatures over a period of 10 years. While we expected to see little variation over this short time span, the results were quite interesting. The effects of known station location changes were evident, particularly in their impact on mean minimum temperatures. Smooth changes were evident in other cases, though the mean minimum temperatures again varied to a greater degree than mean maximum temperatures. Collectively, these empirical results raise questions about the interpretation of climatological time series associated with arbitrarily selected stations from the NWS COOP network, including stations that are part of the USHCN.

Biased data from individual observing stations contribute to uncertainty and error in regional or large-scale climatological studies. Hegerl et al. (2001) noted that error is introduced into gridded data through varying densities of station data. Their study found that sampling error due to station density may increase uncertainty in the climate signal by about $2-6 \%$ and $3-8 \%$ for the first and second half of the twentieth century, respectively, for anthropogenic climate change. Errors are likely to be magnified in areas where the network of observing stations is low. We suggest that biased data would also affect quality of sampling and magnify these errors and, consequently, affect the accuracy of climate change prediction. Pielke et al. (2002b) noted that the regional scale discrepancy between observed and modeled data ranges between 3 and $9{ }^{\circ} \mathrm{C}$. They have recommended the use of spatial accuracy tests, comparison with the historic data, and uncertainty estimates when large-scale global circulation model (GCM) data are used for various regional assessments. GeoProfiles 
should be integrated as part of these activities. A concerted effort is needed on a nationwide scale to enhance the quality of COOP sites and develop detailed spatial metadata, as contained in the GeoProfile. Numerous stations nationally and internationally are closed or relocated each year, and the value of the climatological records associated with these stations is compromised by the lack of information about possible biases that may contaminate the time series.

Finally, further research is needed to address the impacts of instrument exposure on temperature observations. GeoProfiles can play an important role in this type of research. This paper clearly demonstrates the importance and utility of GeoProfiles and the urgency for building such a metadata base. GeoProfiles can provide quantitative information on land use, slope, and aspect for any defined scales. Hence, the influence of micro- and meso-scale features on temperature can be identified. Several robust procedures for temperature bias adjustment have been developed in conjunction with building the USHCN database (e.g. Easterling and Peterson, 1995; Karl et al., 1986, 1988, 1990; Karl and Williams, 1987; Peterson and Easterling, 1994; Quayle et al., 1991). The authors of this paper suggest development of dynamic bias correction procedures that would be able to respond to changes in exposure over a period time.

Schmid and Oke (1990) and Schmid et al. (1991) developed a method to identify source regions of an air parcel and the influence of land use on the characteristics of these air parcels at micro-scales. They have successfully applied this method for complex urban land use and for urban meteorological studies. In a similar vein, we suggest that research addressing the varying influence of atmospheric conditions with seasonal changes can lead to a better understanding of the biases associated with instrument exposure. While it is not possible to go back and adequately reconstruct the instrument exposures of most historical stations, the knowledge gained from research can still aid the scientific community when choosing stations for use in climatological research.

\section{ACKNOWLEDGEMENTS}

The authors would like to thank Shawn Simpson, Ashley Littell, and Seth McDowell for technical assistance. Cooperation provided by the NWS and COOP observers during site visits is much appreciated.

\section{REFERENCES}

Adegoke JO, Pielke RA Sr, Eastman J, Mahmood R, Hubbard KG. 2003. Impact of irrigation on mid summer surface fluxes and temperature under dry synoptic conditions: a regional atmospheric model study of the U. S. High Plains. Monthly Weather Review 131: $556-564$.

Aguilar E, Auer I, Brunet M, Peterson T, Wieringa J. 2003. Guidelines on climate metadata and homogenization. WCDMP-No 53, WMO-TD No 1186. World Meteorological Organization: Geneva, 51.

Allen RJ, DeGaetano AT. 2000. A method to adjust long-term temperature extreme series for nonclimatic inhomogeneities. Journal of Climate 13: 3680-3694.

Arnfield AJ. 2003. Two decades of urban climate research: a review of turbulence, exchanges of energy and water, and urban heat island. International Journal of Climatology 23: 1-26.

Balling RC Jr. 1988. The climatic impacts of a sonoran vegetation discontinuity. Climatic Change 13: 99-109.

Balling RC Jr, Klopatek JM, Hilderbrandt ML, Moritz CK, Watts CJ. 1998. Impacts of land degradation on historical temperature records from the sonoran desert. Climatic Change 40: 669-681.

Bonan G. 1999. Observational evidence for reduction of daily maximum temperature by croplands in the Midwest United States. Journal of Climate 14: 2430-2442.

Cayan DR, Douglas AV. 1984. Urban influences on surface temperatures in the southwestern United States during recent decades. Journal of Applied Meteorology 23: 1520-1530.

Davey CA, Pielke RA Sr. 2005. Microclimate exposures of surface-based weather stations-implications for the assessment of long-term temperature trends. Bulletin of the American Meteorological Society 86: 497-504.

Easterling DR, Peterson TC. 1995. A new method of detecting undocumented discontinuities in climatological time series. International Journal of Climatology 15: 369-377.

Epperson DL, David JM, Bloomfield P, Karl TR, McNab AL, Gallo KP. 1995. Estimating the urban bias of surface shelter temperatures using upper-air and satellite data. Part I: development of models predicting surface shelter temperatures. Journal of Applied Meteorology 34: 340-357.

Gallo KP, Easterling DR, Peterson TC. 1996. The influence of land use/land cover on climatological values of the diurnal temperature ranges. Journal of Climate 9: 2941-2944.

Gallo KP, Owen TP, Easterling DR. 1999. Temperature trends of the U. S. historical climatology network based on satellite-designated land use/land cover. Journal of Climate 12: 1344-1348.

Hegerl GC, Jones PD, Barnett TP. 2001. Effect of observational sampling error on the detection of anthropogenic climate change. Journal of Climate 14: 198-207. 
Horvitz AH, Leffler RJ. 2002. Cooperative Observer Program (COOP) modernization. In Preprints, 13th Conference on Applied Climatology, Portland, Oregon 1-3.

Hubbard KG, Lin X. 2002. Realtime data filtering models for air temperature measurements. Geophysical Research Letters 29(10): 1425: DOI:10.10292001GL013191.

Hubbard KG, Lin X, Walter-Shea EA. 2001. The effectiveness of the ASOS MMTS, Gill, CRS air temperature radiation shields. Journal of Atmospheric and Oceanic Technology 18: 851-864.

Janis MJ. 2002. Observation-time-dependent biases and departures for daily minimum and maximum temperatures. Journal of Applied Meteorology 41: 588-603.

Janis MJ, Hubbard KG, Redmond KT. 2004. Station density strategy for monitoring long-term climatic change in the contiguous United States. Journal of Climate 17: 151-162.

Jones PD, Moberg A. 2003. Hemispheric and large-scale surface air temperature variations: an extensive revision and an update to 2001. Journal of Climate 16: 206-223.

Karl TR, Williams CW Jr. 1987. An approach to adjusting climatological time series for discontinuous inhomogeneities. Journal of Climate and Applied Meteorology 26: 1744-1763.

Karl TR, Diaz HF, Kukla G. 1988. Urbanization: its detection and effect in the United States climate record. Journal of Climate 1: 1099-1123.

Karl TN, Williams CN Jr, Quinlan FT. 1990. United States Historical Climatology Network (HCN) serial temperature and precipitation data. ORNL/CDIAC-30, NDP-019/R1. Carbon Dioxide Information Analysis Center, Oak Ridge National Laboratory: Oak Ridge, TN.

Karl TR, Williams CN Jr, Young PJ, Wendland WM. 1986. A model to estimate the time of observation bias associated with monthly mean maximum, minimum, and mean temperature for the United States. Journal of Climate and Applied Meteorology 25: $145-160$.

Kukla G, Gavin J, Karl TR. 1986. Urban warming. Journal of Applied Meteorology 25: 1265-1270.

Lin X, Hubbard KG, Walter-Shea EA. 2001a. Air flow characteristics of commonly used temperature radiation shields. Journal of Atmospheric and Oceanic Technology 18: 329-339.

Lin X, Hubbard KG, Walter-Shea EA. 2001b. Radiation loading model for evaluating air temperature errors with non-aspirated radiation shield. Transactions of the ASAE 44: 1299-1306.

Lin X, Hubbard KG, Walter-Shea EA, Brandle JR, Meyer GE. 2001c. Some perspective on recent temperature observations: modeling the microclimate inside the radiation shields. Journal of Atmospheric and Oceanic Technology 18: 1470-1484.

Lund R, Reeves J. 2002. Detection of undocumented change points: a revision of the two-phase regression model. Journal of Climate 15: $2547-2554$.

Mahmood R, Hubbard KG. 2002. Anthropogenic land use change in the North American tall grass-short grass transition and modification of near surface hydrologic cycle. Climate Research 21: 83-90.

Mahmood R, Hubbard KG. 2003. Simulating sensitivity of soil moisture and evapotranspiration under heterogeneous soils and land uses. Journal of Hydrology 280: 72-90.

Mahmood R, Hubbard KG. 2004. An analysis of simulated long-term soil moisture data for three land uses under contrasting hydroclimatic conditions in the northern great plains. Journal of Hydrometeorology 5: 160-179.

Mahmood R, Hubbard KG, Carlson C. 2002. Land use change and modification of near-surface thermal records in the northern great plains. Bulletin of the American Meteorological Society 83: 504.

Mahmood R, Hubbard KG, Christy C. 2004. Modification of growing season surface temperature records in the northern great plains due to land use transformation: verification of modeling results and implication for global climate change. International Journal of Climatology 24: 311-327.

National Research Council. 1998. Future of the National Weather Service Cooperative Network. National Academies Press: Washington. Parker D. 2004. Large-scale warming is not urban. Nature 432: 290.

Peterson TC. 2003. Assessment of urban versus rural in situ surface temperatures in the contiguous United States: No difference found. Journal of Climate 16: 2941-2959.

Peterson TC, Easterling DR. 1994. Creation of homogeneous composite climatological reference series. International Journal of Climatology 14: 671-680.

Pielke RA Sr. 2002. Overlooked issues in the U. S. national climate and IPCC assessments: an editorial essay. Climatic Change 52: $1-11$.

Pielke RA Sr, Stohlgren T, Parton W, Doesken N, Money J, Schell L, Redmond K. 2000. Spatial representativeness of temperature measurements from a single site. Bulletin of the American Meteorological Society 81: 826-830.

Pielke RA Sr, Marland G, Betts RA, Chase TN, Eastman JL, Niles JO, Niyogi DDS, Running SW. 2002a. The influence of land-use change and landscape dynamics on the climate system: relevance to climate-change policy beyond the radiative effect of greenhouse gases. Philosophical Transactions of the Royal Society of London Series A 360: 1705-1719.

Pielke RA Sr, Stohlgren T, Schell L, Parton W, Doesken N, Redmond K, Money J, Mckee T, Kittel TGF. 2002b. Problems in evaluating regional and local trends in temperature: an example from eastern Colorado, USA. International Journal of Climatology 22: $421-434$.

Quayle RG, Easterling DR, Karl TR, Hughes PY. 1991. Effects of recent thermometer changes in the cooperative network. Bulletin of the American Meteorological Society 72: 1718-1724.

Schaal LA, Dale RF. 1977. Time of observation temperature bias and "climatic change". Journal of Applied Meteorology 16: 215-222.

Schmid HP, Oke TR. 1990. A model to estimate the source area contributing to turbulent exchange in the surface layer over patchy terrain. Quarterly Journal of the Royal Meteorological Society 116: 965-988.

Schmid HP, Cleugh HA, Grimmond CSB, Oke TR. 1991. Spatial variability of energy fluxes in suburban terrain. Boundary-Layer Meteorology 54: 249-276.

Segal M, Schreiber WE, Kallos G, Garratt GR, Rodi A, Weaver J, Pielke RA. 1989. The impact of crop areas in northeastern Colorado on midsummer mesoscale thermal circulations. Monthly Weather Review 117: 809-825.

Vincent LA. 1998. A technique for the identification of inhomogeneities in Canadian temperature series. Journal of Climate 11: $1094-1104$. 